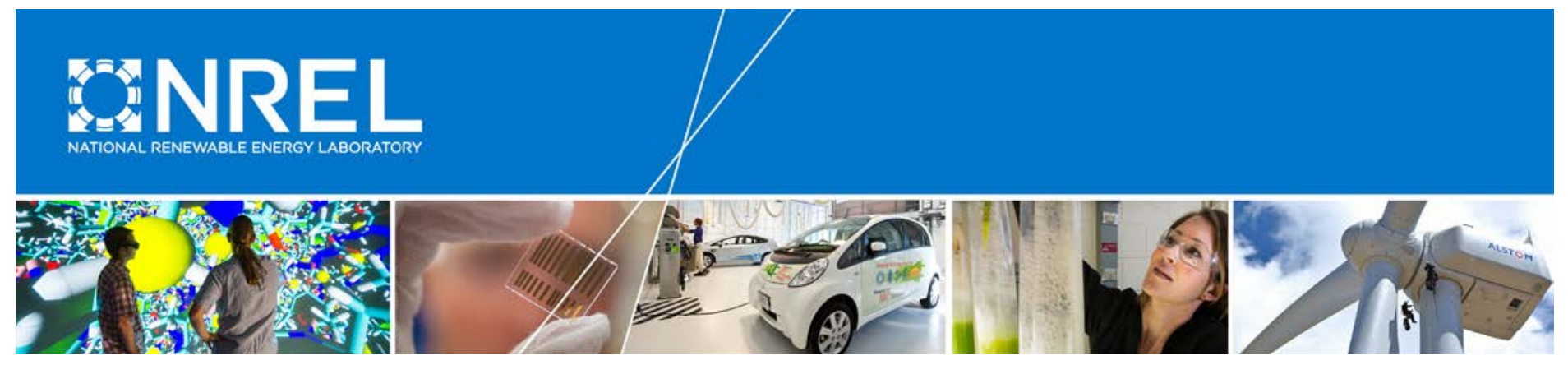

\title{
Implications of Model Structure and Detail for Utility Planning: Scenario Case Studies Using the Resource Planning Model
}

Trieu Mai, Clayton Barrows, Anthony Lopez, Elaine Hale, Mark Dyson, and Kelly Eurek National Renewable Energy Laboratory

NREL is a national laboratory of the U.S. Department of Energy Office of Energy Efficiency \& Renewable Energy Operated by the Alliance for Sustainable Energy, LLC

This report is available at no cost from the National Renewable Energy Laboratory (NREL) at www.nrel.gov/publications.

Technical Report

NREL/TP-6A20-63972

April 2015

Contract No. DE-AC36-08GO28308 


\section{Implications of Model Structure and Detail for Utility Planning: Scenario Case Studies Using the Resource Planning Model}

Trieu Mai, Clayton Barrows, Anthony. Lopez, Elaine Hale, Mark Dyson, and Kelly Eurek National Renewable Energy Laboratory

Prepared under Task Nos. SA15.0910, SA12.0381, and DRS8.3070

NREL is a national laboratory of the U.S. Department of Energy Office of Energy Efficiency \& Renewable Energy Operated by the Alliance for Sustainable Energy, LLC

This report is available at no cost from the National Renewable Energy Laboratory (NREL) at www.nrel.gov/publications.

National Renewable Energy Laboratory 15013 Denver West Parkway Golden, CO 80401

303-275-3000 • www.nrel.gov
Technical Report

NREL/TP-6A20-63972

April 2015

Contract No. DE-AC36-08G028308 


\title{
NOTICE
}

This report was prepared as an account of work sponsored by an agency of the United States government. Neither the United States government nor any agency thereof, nor any of their employees, makes any warranty, express or implied, or assumes any legal liability or responsibility for the accuracy, completeness, or usefulness of any information, apparatus, product, or process disclosed, or represents that its use would not infringe privately owned rights. Reference herein to any specific commercial product, process, or service by trade name, trademark, manufacturer, or otherwise does not necessarily constitute or imply its endorsement, recommendation, or favoring by the United States government or any agency thereof. The views and opinions of authors expressed herein do not necessarily state or reflect those of the United States government or any agency thereof.

This report is available at no cost from the National Renewable Energy Laboratory (NREL) at www.nrel.gov/publications.

Available electronically at SciTech Connect http:/www.osti.gov/scitech

Available for a processing fee to U.S. Department of Energy and its contractors, in paper, from:

\author{
U.S. Department of Energy \\ Office of Scientific and Technical Information \\ P.O. Box 62 \\ Oak Ridge, TN 37831-0062 \\ OSTI http://www.osti.gov \\ Phone: 865.576.8401 \\ Fax: 865.576.5728 \\ Email: reports@osti.gov
}

Available for sale to the public, in paper, from:

\author{
U.S. Department of Commerce \\ National Technical Information Service \\ 5301 Shawnee Road \\ Alexandra, VA 22312 \\ NTIS http://www.ntis.gov \\ Phone: 800.553 .6847 or 703.605 .6000 \\ Fax: 703.605.6900 \\ Email: orders@ntis.gov
}




\section{Acknowledgments}

We thank Nate Blair, Aaron Bloom, Greg Brinkman, Wesley Cole, Karlynn Cory, Paul Denholm, Eduardo Ibanez, and Dave Mooney (National Renewable Energy Laboratory), Andrew Mills (Lawrence Berkeley National Laboratory), Brendan Kirby, Jimmy Nelson (Union of Concerned Scientists), and Walter Short for their thoughtful reviews, comments, and suggestions. We also thank Sam Baldwin, Gil Bindewald, and Ookie Ma (U.S. Department of Energy) for supporting this work. Easan Drury (National Renewable Energy Laboratory, formerly) deserves our special gratitude for his thought leadership and insights at the inception of the Resource Planning Model. This research was funded by the U.S. Department of Energy under contract number DE-AC36-08GO28308. Any remaining errors or omissions are the sole responsibility of the authors. 


\section{Abstract}

Capacity expansion models are computational tools designed to find the least cost option for planning a system under a variety of policy, business, and operational constraints. In this report, we analyze the impacts of model configuration and detail on resource selection decisions of capacity expansion models. Our analysis focuses on the importance of model configurationsparticularly those related to capacity credit, dispatch modeling, and transmission modeling - to the construction of scenario futures. Our analysis is primarily directed toward advanced tools used for utility planning and those impacts that are most relevant to decisions about future renewable capacity deployment. To serve this purpose, we develop and employ the National Renewable Energy Laboratory's Resource Planning Model to conduct a case study analysis that explores 11 capacity expansion model configuration scenarios for the Western Interconnection through 2030. While the analysis results cover the entire Western Interconnection, the model and research examine in greater detail a region within the interconnection that consists of two balancing areas - the Public Service Company of Colorado and the Western Area Power Administration Colorado/Missouri-that serve load primarily in and around the state of Colorado.

We examine how model investment decisions change under different model configurations and assumptions related to renewable capacity credit, the inclusion or exclusion of operating reserves, dispatch period sampling, transmission power flow modeling, renewable spur line costs, and the ability of a planning region to import and export power. For all modeled scenarios, we find that under market conditions where new renewable deployment is predominantly driven by renewable portfolio standards, model representations of wind and solar capacity credit and interactions between balancing areas are most influential in avoiding model investments in excess thermal capacity. We also compare computation time between configurations to evaluate tradeoffs between computational burden and model accuracy. From this analysis, we find that certain advanced dispatch representations (e.g., DC optimal power flow) can have dramatic adverse effects on computation time but can be largely inconsequential to model investment outcomes, at least at the renewable penetration levels modeled. Finally, we find that certain underappreciated aspects of new capacity investment decisions and model representations thereof, such as spur lines for new renewable capacity, can influence model outcomes particularly in the renewable technology and location chosen by the model. Though this analysis is not comprehensive and results are specific to the model region, input assumptions, and optimization-modeling framework employed, the findings are intended to provide a guide for model improvement opportunities. 


\section{Table of Contents}

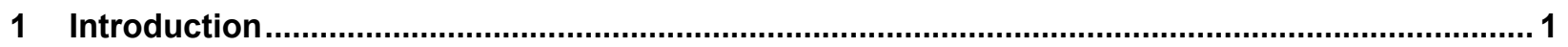

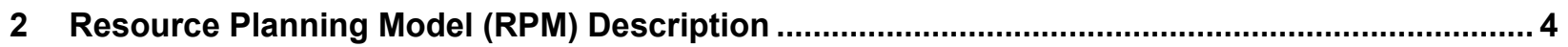

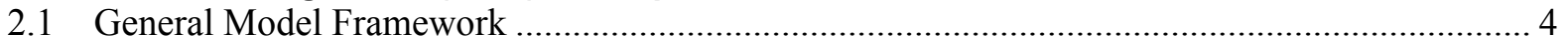

2.2 Model Spatial-Temporal Structure and Initial Conditions ..................................................... 5

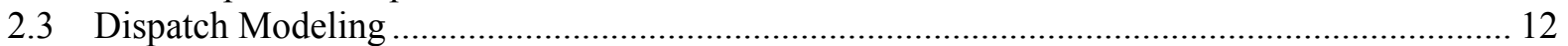

2.4 Investment Decision Assumptions and Drivers ....................................................................... 15

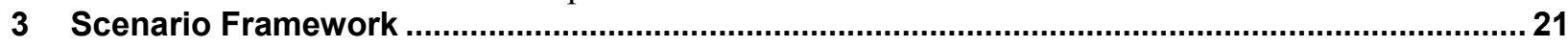

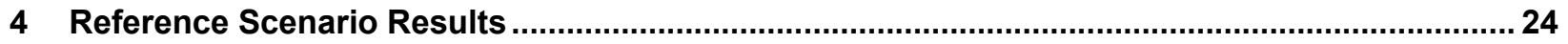

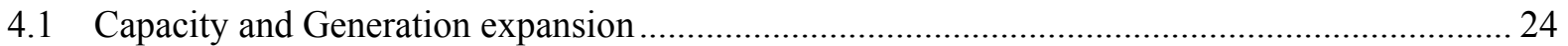

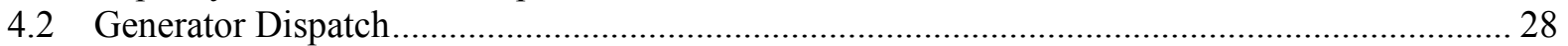

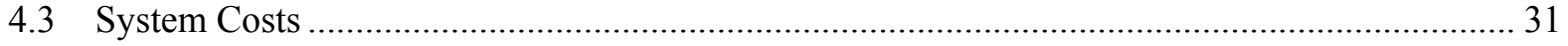

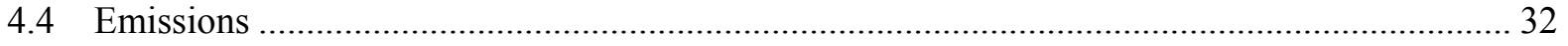

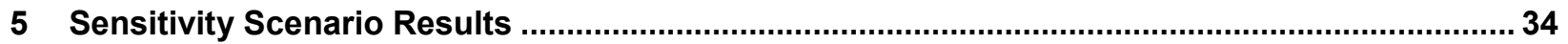

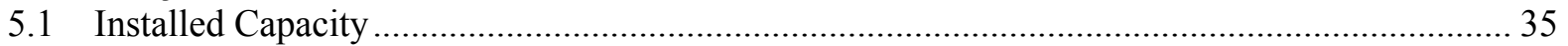

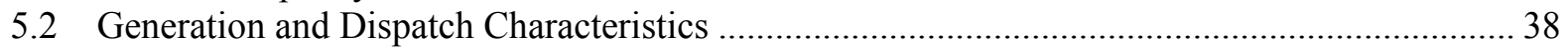

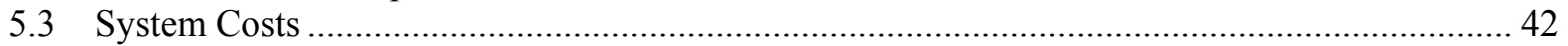

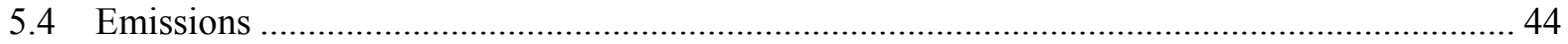

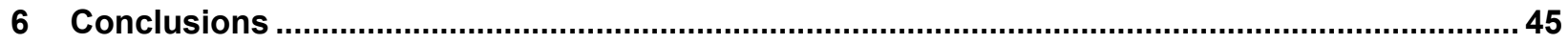

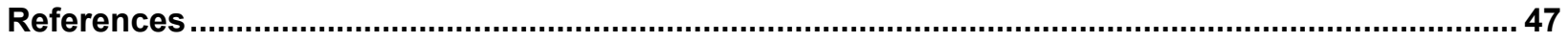

Appendix - Comparison of RPM Results with Historical Generation .............................................. 52 


\section{List of Figures}

Figure 1. Western Interconnection power system as represented in the RPM database ........................ 8

Figure 2. Combined zonal/nodal structure used for the CO-centric version of RPM .............................. 9

Figure 3. Solar (left) and wind (right) resource regions modeled in the CO-centric version of RPM for

the U.S. portion of the Western Interconnection ............................................................. 11

Figure 4. CO-centric focus region demand clustered in 'LOW', 'MID', 'HIGH', and 'PEAK DAY' periods .. 13

Figure 5. Assumed natural gas, coal, and uranium prices from 2010 to 2030 (EIA 2014) ...................... 18

Figure 6. Western Interconnection installed capacity (left) and annual generation (right) from 2010 to

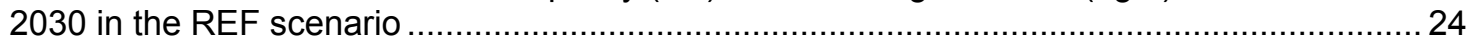

Figure 7. CO-centric focus region installed capacity (left) and annual generation (right) from 2010 to 2030 in the REF scenario....

Figure 8. Average (over resource-weighted resource regions) marginal capacity credit for wind and solar technologies, for the CO-centric focus region and the Western Interconnection, as calculated in the REF scenario.

Figure 9. Installed wind (left) and solar (right) capacity in Colorado and surrounding regions under the REF scenario in 2030

Figure 10. Installed capacity in 2010 (left) and estimated total capacity (including additions) in 2030 (right) for all nodes within the focus region.....

Figure 11. Western Interconnection dispatch stacks by dispatch period and year under the REF scenario

Figure 12. CO-centric focus region dispatch stacks by dispatch period and year under the REF scenario

Figure 13. Annual reserve provision in the CO-centric focus region for regulation (reg), spinning (spin), and flexibility (flex) reserve products in the REF scenario

Figure 14. Net present value of system costs for 2015-2030, with a 3\% real discount rate, for the Western Interconnection under the REF scenario

Figure 15. $\mathrm{CO}_{2}$ emissions (left) and $\mathrm{CO}_{2}$ intensity (right) for the Western Interconnection under the REF scenario

Figure 16. Computation time for each model configuration scenario

Figure 17. Differences in 2030 installed capacity (relative to the REF scenario) across the entire Western Interconnection (left) and the focus region (right) for all 10 sensitivities. 35

Figure 18. Capacity and location of wind (top) and PV Tracking (bottom) in 2030 for the REF scenario (left) and the FCON scenario (right)

Figure 19. Differences in CO-centric focus region capacity (relative to the REF scenario) for each solve year (2010-2030) for the DCOPF (left) and CP (right) scenarios ....

Figure 20. Differences in 2030 annual generation (relative to the REF scenario) across the entire Western Interconnection (left) and the CO-centric focus region (right) for all 10 sensitivities .. 39

Figure 21. 'LOW' dispatch period CO-centric focus region 2030, by-technology for the REF, 1DAY, $\mathrm{MR}$, and IFR scenarios

Figure 22. 'HIGH' dispatch period CO-centric focus region 2030, by-technology dispatch for the REF, 1DAY, MR, and IFR scenarios

Figure 23. Dispatch stacks for system operation in 2030 for each of the four dispatch periods (LOW and $\mathrm{HIGH}$ ) for the 4DAY model configuration scenario.

Figure 24. Differences in the NPV of system costs (relative to the REF scenario) in all 10 single-feature sensitivities

Figure 25. Differences in Western Interconnection annual $\mathrm{CO}_{2}$ emissions in 2030 (relative to the REF scenario)

Figure A. Annual generation for 2010: historical EIA and EPA (eGRID) data, and RPM results from the REF scenario...

Figure B. Annual generation for 2010: historical EPA (eGRID) data and the RPM REF scenario for the RMRG focus region 


\section{List of Tables}

Table 1. Balancing Areas (BAs) Modeled in the Resource Planning Model............................................ 6

Table 2. Start Year (2010) Capacity in the Resource Planning Model ............................................... 10

Table 3. Technology Cost and Performance Assumptions for New Generation Capacity ....................... 16

Table 4. Scenario Framework and Definitions .............................................................................. 22 


\section{Introduction}

Electricity system capacity expansion models (CEMs) are computational tools used to generate future scenarios, including the quantity, mix, and location of new generation capacity. These models vary widely in structure, geographic scope, system operations detail, and solution method. ${ }^{1}$ The purposes and users of CEMs are similarly diverse and include researchers, government agencies, and electric utility planners. This report is focused on the class of models used by utility planners and is intended to inform model design and selection within this model class. In particular, we present modeling issues relevant to utility planning tools. However, the modeling considerations laid out in this report can also be applied to other classes of CEMs (e.g. national- or global- scale models).

The role of electric utility resource planners is to identify portfolios of new resources that will allow a utility to meet its obligation to serve its customers at the least possible cost, risk, or related metric. ${ }^{2}$ The utility plans are referred to as integrated resource plans (IRPs), electric resource plans (ERP), long-term procurement plans (LTPP), and other similar names. Recent work (Wilkerson, Larsen, and Barbose 2013; Wilson and Biewald 2013, Aspen/E3 2008) lays out the process of utility resource planning and provides surveys of utility resource plans and procurement practices. For those utility planning processes that use a CEM or other analytic tool, the general process follows several basic steps. Planners first assess the state of current resources, develop demand expectations, and compare the future availability of current resources against those expectations. Potential investment plans are created by inputting existing generating resources, load growth, and new resource options into a CEM or other analytic tool, and various parameters or constraints are used to represent future states of the world (e.g., fuel prices, demand levels, policy requirements). The future operating costs of candidate portfolios identified by the CEM are sometimes simulated using production cost models (PCMs), which model the fuel, maintenance, and other variable costs of resource portfolios in more detail than the simplified representation of these costs in CEMs. Finally, a preferred portfolio is selected. ${ }^{3}$

Recent growth in renewable generation, along with other developments such as market restructuring and greater interactions across balancing authorities, has increasingly complicated the planning process, particularly with software tools that were not designed to account for the resource characteristics of some renewable technologies - variability, uncertainty, and inherent location dependence. ${ }^{4}$ Integrated resource plans are increasingly reporting several parameters of renewable resources that are distinct from those of traditional thermal generators and thus need different treatment within CEMs. Details on these characteristics are presented in recent

\footnotetext{
${ }^{1}$ Sullivan, Eurek, and Margolis (2014) summarizes a wide range of CEMs.

${ }^{2}$ We use the term "utility resource planner" in a broad sense to refer to planners from load serving entities, investorowned utilities, independent power producers, state and municipal utilities, electric cooperatives, and other such entities. This discussion can also apply to others associated with evaluating future resource options for regional power systems, such as regional transmission operators, power authorities, regulators, state or local government agencies, and others.

${ }^{3}$ Once a preferred portfolio is selected, procurement processes or regulatory approval processes commence for the needed new infrastructure.

${ }^{4}$ For definitional purposes, we define variable technologies as those where the maximum available power output varies from one time period to the next (e.g., hour to hour) and uncertainty as the inability to perfectly predict future available power.
} 
overview work for solar (Mills and Wiser 2012; Sterling et al. 2013) and for wind (Ensslin et al. 2008; Milligan and Kirby 2009). While we do not provide a comprehensive survey of software tools used for utility resource planning, this introduction presents examples of approaches used to address capacity credit, integration costs, transmission, and boundary conditions or other interactions with neighboring entities. ${ }^{5}$ Some of the issues outlined below are considered in the planning process by using detailed production cost models. Our analysis focuses exclusively on CEMs. In particular, we explore three key aspects associated with renewable electricity options in CEMs: capacity credit, generation dispatch modeling, and transmission modeling. ${ }^{6}$

Capacity credit refers to the portion of nominal plant capacity that is relied on to help meet peak load. Methods of estimating capacity credit include loss of load probability (LOLP), peak-hour average capacity factors, and engineering judgment (Castro and Ferreira 2001; Perez et al. 2008). While a LOLP-based method provides the most robust estimate (Madaeni et al. 2012), recent integrated resource plans and similar documents show that relatively few utilities conduct such reliability-oriented studies (Mills and Wiser 2012), in part due to the complexity of LOLP calculations and the difficulty of implementing them within a CEM structure. Independent of estimation metric, CEMs typically do not dynamically estimate renewable capacity credit to account for the effects of different penetration levels, technology mix, or location, even though such effects are known to be significant (Sigrin et al. 2014). Exceptions do exist, as at least one utility in the western United States explicitly models how marginal solar capacity credit declines with increasing penetration (Arizona Public Service 2012). Although the declining capacity credit effect exists for wind as well (Ensslin et al. 2008), but it is frequently not considered within the planning tools, but is instead often estimated outside the models.

Many utility planners apply an integration cost adder to the cost of new renewable capacity or energy production. These costs are included in CEMs as a proxy for a suite of issues, including the cost of balancing, forecast errors, system upgrades, as well as other costs related to accommodating variable generation in power systems. Because the causation of costs and the justification for their magnitude vary between studies, a comparison is not straightforward. Nonetheless, common values for solar range from $\$ 2 / \mathrm{MWh}-\$ 11 / \mathrm{MWh}$, and for wind from \$1/MWh-\$9/MWh (Mills and Wiser 2012; DeCesaro, Porter, and Milligan 2009). Recent studies outline some common pitfalls in calculating integration costs and including them in planning studies, and only a few planning jurisdictions perform the detailed, system- and portfolio-specific integration cost studies that are deemed most accurate in the literature (Mills and Wiser 2012, Milligan et al. 2011). These integration costs are traditionally applied, in part, due to the historically limited ability of CEMs to capture systems operation and transmission in detail. However, integration costs can inaccurately represent the costs associated with managing variability, do not account for the dynamic nature of these costs as the system evolves, are not universally accepted in the industry, lack uniformity in factors included and development methodology, and are inconsistently applied across technologies.

\footnotetext{
${ }^{5}$ Foley et al. (2010) describes some of the electric system models used in utility resource planning. In addition, many planners rely on "in-house" tools that are not accessible for comparison (Mills and Wiser 2012).

${ }^{6}$ Sterling et al. (2013) point out that utility planners also only consider renewable options to meet RPS mandates and do not consider renewable capacity beyond that as an economically competitive option. In addition, renewable technologies on the distribution side (e.g., rooftop PV) are also treated simply by some planners. These issues and others presented by Sterling et al. (2013) are beyond the scope of the present analysis.
} 
Because transmission planning groups are often distinct from generation planning groups, transmission expansion studies are often conducted independently of generation expansion studies. Many planning studies include transmission costs as part of the cost for new resources, ${ }^{7}$ but it is less common to explicitly co-optimize transmission network expansion with candidate generation portfolios (Mills and Wiser 2012, Liu et al. 2013). Sterling et al. (2013) found that only one utility of 13 entities they interviewed performed an integrated analysis of generation and transmission expansion options. Transmission and generation co-optimization is typically not an option in CEMs. In addition to the expansion problem, transmission constraints in CEMs are typically modeled using simple algorithms (e.g., copper sheet or zonal transportation models). ${ }^{8}$ These methods fail to fully capture the spatiotemporal-dependent costs and benefits of electrical generation and consumption patterns.

Utility planning studies also vary in their treatment of off-system sales or purchases for energy or capacity. Some utilities included the option to buy or sell power from neighboring utilities or third party generators explicitly or indirectly within the CEM and/or PCM (Seattle City Light 2012; Avista 2011; Portland General Electric 2009; Idaho Power 2011, Xcel Energy 2011; Arizona Public Service 2012), while others did not include such market interactions in order to ensure that their system would not rely on other parties' investments (PNM 2011; Tri-State Generation \& Transmission 2010). ${ }^{9}$ Some others do not report the method used to determine future price levels for purchased or sold power (e.g., LADWP 2011).

As noted by Mills and Wiser (2012) and Sterling et al. (2013), the common approaches to modeling transmission expansion and market interactions imperfectly model the expansionplanning problem with renewables. First, the lack of co-optimization of transmission and generation resources results gives a potentially sub-optimal solution. Second, the omission from a CEM or PCM of off-system sales or purchases can exclude potential options for reducing system operating costs. In addition, simplified boundary conditions do not generally incorporate explicit assumptions about the renewable capacity additions in neighboring regions, which can misrepresent the value of building new renewable resources within a utility's jurisdiction.

In this report, we evaluate how CEM configuration can impact scenario results. We use a new capacity expansion model — the National Renewable Energy Laboratory's (NREL's) Resource Planning Model (RPM) - to demonstrate how model treatment of transmission, geographical boundary conditions (including potential for off-system sales and purchases), power system operations and related dispatch representations, and renewable capacity credit can change scenario results. In particular, we compare how simplified configuration variants of RPM can lead to results that are different from those of more-detailed versions of the model. Because simplifying assumptions are needed in all model representations, this analysis informs prioritization decisions when simplifications are necessary.

\footnotetext{
${ }^{7}$ Some planning studies reduce transmission costs for portfolios that contain local resources, including solar photovoltaics (PV).

${ }^{8}$ Copper sheet refers to a model without any transmission constraints included. Transportation models represent electricity transmission in the same manner as mass transport, instead of using electromagnetic laws of physics that are more realistic.

${ }^{9}$ Arbitrage opportunities within PCM are sometimes allowed in such cases.
} 
The development of the RPM and our research on the effects of model representation for renewable technologies is informed by other recent electric system modeling efforts aimed toward improved system flexibility or variable generation modeling. These include those by Welsh et al. (2014) and Ma et al. (2013) on representing flexibility in long-term planning models, Nelson et al. (2012) on modeling the Western Interconnection, and Palmintier (2013) on techniques for simplified unit commitment modeling. In addition, Shawhan et al. (2014) focuses on the importance of model detail to understand the impacts of greenhouse gas policies. Our current effort is intended to build on this broader electric sector modeling research.

Section 2 provides a description of RPM. Section 3 describes the scenarios modeled. Section 4 provides a detailed description of the reference scenario, while the appendix compares the 2010 model dispatch results of this scenario with historical generation. Section 5 presents a comparative analysis of the reference scenario results and other model variants. We conclude in Section 6 .

\section{Resource Planning Model Description}

\subsection{General Model Framework}

The NREL's Resource Planning Model (RPM) is a capacity expansion model designed for a regional power system, such as a utility service territory, state, or balancing authority. It is an optimization model that finds the least-cost investment and dispatch solution over a 20 -year horizon. The model investment decisions are made for multiple conventional and renewable generation technologies, storage technologies, and transmission. The model has high spatial resolution to represent the grid network (down to the individual unit and line) and multiple solar and wind spatial resource regions. Dispatch modeling within RPM is conducted using hourly time-steps sampled throughout a year, and the model considers energy balance, reserves, and many generator constraints. Transmission constraints are represented with a linearized DC power flow algorithm, or a transport (pipe-flow) model. A simplified representation of the rest of the interconnection in which the region of interest resides is included in the model to account for boundary interactions. We designed RPM specifically to consider the characteristics of wind and solar technology resources - that is, location-dependence, variability, and uncertainty - in its investment decisions; it accounts for distance-based interconnections, endogenous capacity credits, increased operating reserve requirements, curtailment, transmission congestion, and cycling costs.

The version of the model used for our analysis borrows heavily from an earlier version (Mai et al. 2013); however, significant modifications and upgrades have been made. The general solution method of the present version of RPM is aligned with the earlier version; RPM includes a mixedinteger linear program, and is formulated in the General Algebraic Modeling System (GAMS) language for solution with a number of available solvers. ${ }^{10}$ The RPM optimization problem minimizes overall system cost, including capital costs, fixed and variable operation and maintenance (O\&M) costs, fuel costs, and start-up costs. All costs in the objective function, including operating costs (e.g., fuel and variable O\&M costs) and fixed costs (e.g., amortized

\footnotetext{
${ }^{10}$ Available solver software packages include IBM ILOG CPLEX, GUROBI, SCIP/SOPLEX, and XPRESS-MP, and others. We use CPLEX in our analysis.
} 
capital and fixed O\&M costs), are annualized. Several constraints are designed to characterize power plant operation, transmission dispatch, grid reliability, and capacity expansion. Sections 2.2, 2.3, and 2.4 summarize the key features of the model and highlight those that differ from the version described in Mai et al. (2013).

\subsection{Model Structure and Initial Conditions}

RPM models the Western Interconnection electricity system, which includes all or parts of 13 western states in the United States, two western provinces in Canada, and a small northern region of Mexico. While the spatial extent of RPM covers this wide geographic area, the model is designed for a particular "focus region," with all other regions treated in a simplified manner; that is, RPM is a combined nodal (for nodes within the focus region) and zonal model (for zones outside the focus region). Data from modeling in the Western Wind and Solar Integration Study (WWSIS) Phase 2 study (Lew et al. 2013) ${ }^{11}$ comprise the underlying data for the existing (2010) infrastructure modeled in RPM. ${ }^{12}$ These data include 17,521 nodes, 4,300 generation units, and 21,086 transmission lines. ${ }^{13}$ The nodes are the fundamental spatial unit of the model, and represent buses connected to individual generators and loads, or buses that serve as connection points between transmission elements, e.g., transmission lines and transformers. Model balancing areas (BAs) (see Table 1) make up the zonal structure of RPM. There are 36 model BAs throughout the Western Interconnection, of which one or more are selected to be the focus region. ${ }^{14}$ RPM is adaptable to any focus region in the Western Interconnection through the use of aggregation scripts that take a list of focus region BAs as inputs, operate on a relational database that stores all data in their native resolution, and produce a new RPM database ready for use by the GAMS model as output.

\footnotetext{
11 The WWSIS Phase 2 study relied on data from the Western Electricity Coordinating Council (WECC) Transmission Expansion Planning Policy Committee (TEPPC) 2020 Common Case (WECC 2012) with updates from the TEPPC 2022 Common Case (WECC 2013) along with other revisions as described by Lew et al. (2013).

${ }^{12}$ While the model start year begins in 2010, the data for the 2015 solve year includes many recent capacity additions and retirements. In addition, our analysis is primarily focused on 2015-2030.

${ }^{13}$ Only transmission lines greater than $69 \mathrm{kV}$ are included in the database.

${ }^{14}$ In addition to zonal transmission treatment, generators are aggregated for most technology types for each BA zone to further simplify the model outside of the focus region.
} 
Table 1. Balancing Areas (BAs) Modeled in the Resource Planning Model

\begin{tabular}{|c|c|c|c|c|c|}
\hline \multicolumn{2}{|c|}{ Focus Region BAs } & \multicolumn{4}{|c|}{ Other BAs } \\
\hline PSC & $\begin{array}{l}\text { Public Service } \\
\text { Company of Colorado }\end{array}$ & AESO & $\begin{array}{l}\text { Alberta Electric } \\
\text { System Operator }\end{array}$ & $\begin{array}{l}\text { PG\&E_BA } \\
Y\end{array}$ & $\begin{array}{l}\text { Pacific Gas \& Electric } \\
\text { Bay Area }\end{array}$ \\
\hline \multirow[t]{16}{*}{$\begin{array}{l}\text { WAC } \\
\text { M }\end{array}$} & $\begin{array}{l}\text { Western Area Power } \\
\text { Administration } \\
\text { Colorado/Missouri }\end{array}$ & APS & Arizona Public Service & $\begin{array}{l}\text { PG\&E_VL } \\
Y\end{array}$ & $\begin{array}{l}\text { Pacific Gas \& Electric } \\
\text { Valley Area }\end{array}$ \\
\hline & & AVA & Avista & PGN & $\begin{array}{l}\text { Portland General } \\
\text { Electric }\end{array}$ \\
\hline & & BCTC & $\begin{array}{l}\text { British Columbia } \\
\text { Transmission } \\
\text { Corporation }\end{array}$ & PNM & $\begin{array}{l}\text { Public Service New } \\
\text { Mexico }\end{array}$ \\
\hline & & BPA & $\begin{array}{l}\text { Bonneville Power } \\
\text { Administration }\end{array}$ & PSE & Puget Sound Energy \\
\hline & & CFE & $\begin{array}{l}\text { Comision Federal de } \\
\text { Electricidad }\end{array}$ & SCE & $\begin{array}{l}\text { Southern California } \\
\text { Edison }\end{array}$ \\
\hline & & EPE & $\begin{array}{l}\text { El Paso Electric } \\
\text { Company }\end{array}$ & SCL & Seattle City Light \\
\hline & & FAR_EAST & Far East & SDGE & $\begin{array}{l}\text { San Diego Gas \& } \\
\text { Electric }\end{array}$ \\
\hline & & IID & $\begin{array}{l}\text { Imperial Irrigation } \\
\text { District }\end{array}$ & SMUD & $\begin{array}{l}\text { Sacramento Municipal } \\
\text { District }\end{array}$ \\
\hline & & LDWP & $\begin{array}{l}\text { Los Angeles } \\
\text { Department of Water } \\
\text { and Power }\end{array}$ & SPP & Sierra Pacific Power \\
\hline & & $\begin{array}{l}\text { MAGIC_VL } \\
Y\end{array}$ & Magic Valley & SRP & Salt River Project \\
\hline & & NEVP & Nevada Power & TEP & Tucson Electric Power \\
\hline & & NWMT & Northwestern Montana & TIDC & $\begin{array}{l}\text { Turlock Irrigation } \\
\text { District }\end{array}$ \\
\hline & & PACE_ID & Pacificorp East - Idaho & TPWR & Tacoma Power \\
\hline & & PACE_UT & Pacificorp East Utah & $\begin{array}{l}\text { TREAS_V } \\
\text { LY }\end{array}$ & Treasure Valley \\
\hline & & PACE_WY & $\begin{array}{l}\text { Pacificorp East } \\
\text { Wyoming }\end{array}$ & WALC & $\begin{array}{l}\text { Western Area Power } \\
\text { Administration Lower } \\
\text { Colorado }\end{array}$ \\
\hline & & PACW & Pacificorp West & WAUW & $\begin{array}{l}\text { Western Area Power } \\
\text { Administration Upper } \\
\text { Missouri }\end{array}$ \\
\hline
\end{tabular}


For our analysis, the focus region includes the PSC and WACM BAs. Throughout the report, we refer to this region as the $\mathrm{CO}$-centric focus region, because these two balancing authorities primarily serve loads in Colorado (CO). ${ }^{15}$ The $\mathrm{CO}$-centric focus region includes 1,406 nodes and 1,840 transmission lines, and includes 376 individual generators representing a total of 23,768 MW of installed capacity during the model start year (2010). Outside the focus region, 34 model BAs are represented zonally. The entire Western Interconnection system includes 247,606 MW of generating capacity for the model start year. Interactions between BAs are constrained by interface limits assumed by Lew et al. (2013). Interactions between nodes within the focus region consider nodal transmission constraints defined by the thermal power flow limits on transmission lines. Figure 1 shows the native nodal and transmission infrastructure data included for the Western Interconnection system. In comparison, Figure 2 shows the combined zonal and nodal structure for the CO-centric version of RPM used in our analysis. Table 2 shows the capacity mix by technology category as represented in RPM for the 2010 start year for the focus region and the entire Western Interconnection. Note that while the technology categories are generalized in Table 2, individual unit characteristics (e.g., ramp rates, heat rates, and minimum generation points) from Lew et al. (2013) are used in RPM explicitly for the focus region and averaged by technology category for the BAs in the rest of the Western Interconnection.

${ }^{15}$ The PSCO and WACM BAs also include nodes in Wyoming, Montana, Nebraska, South Dakota, and Utah. 


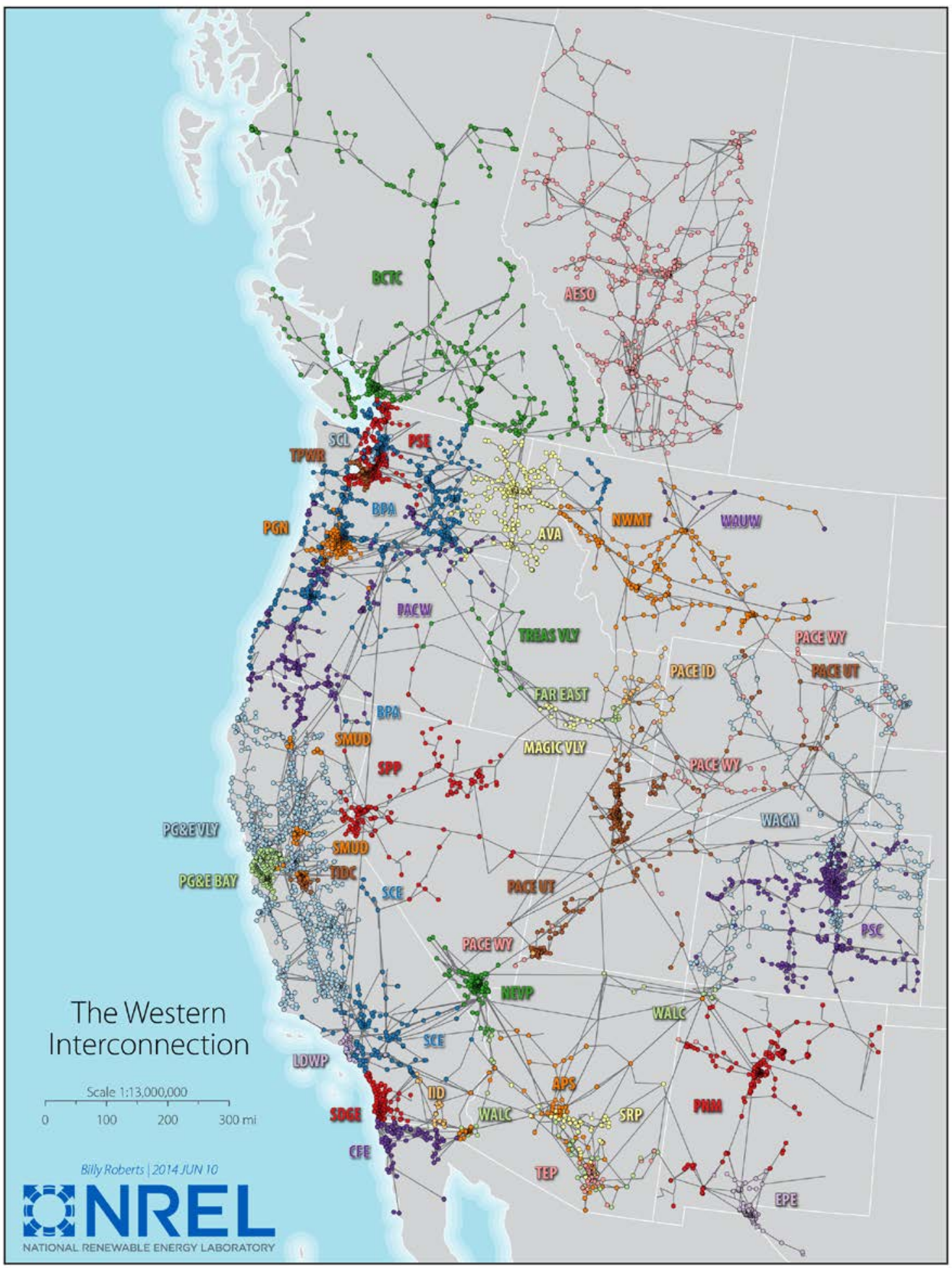

Figure 1. Western Interconnection power system as represented in the RPM database 


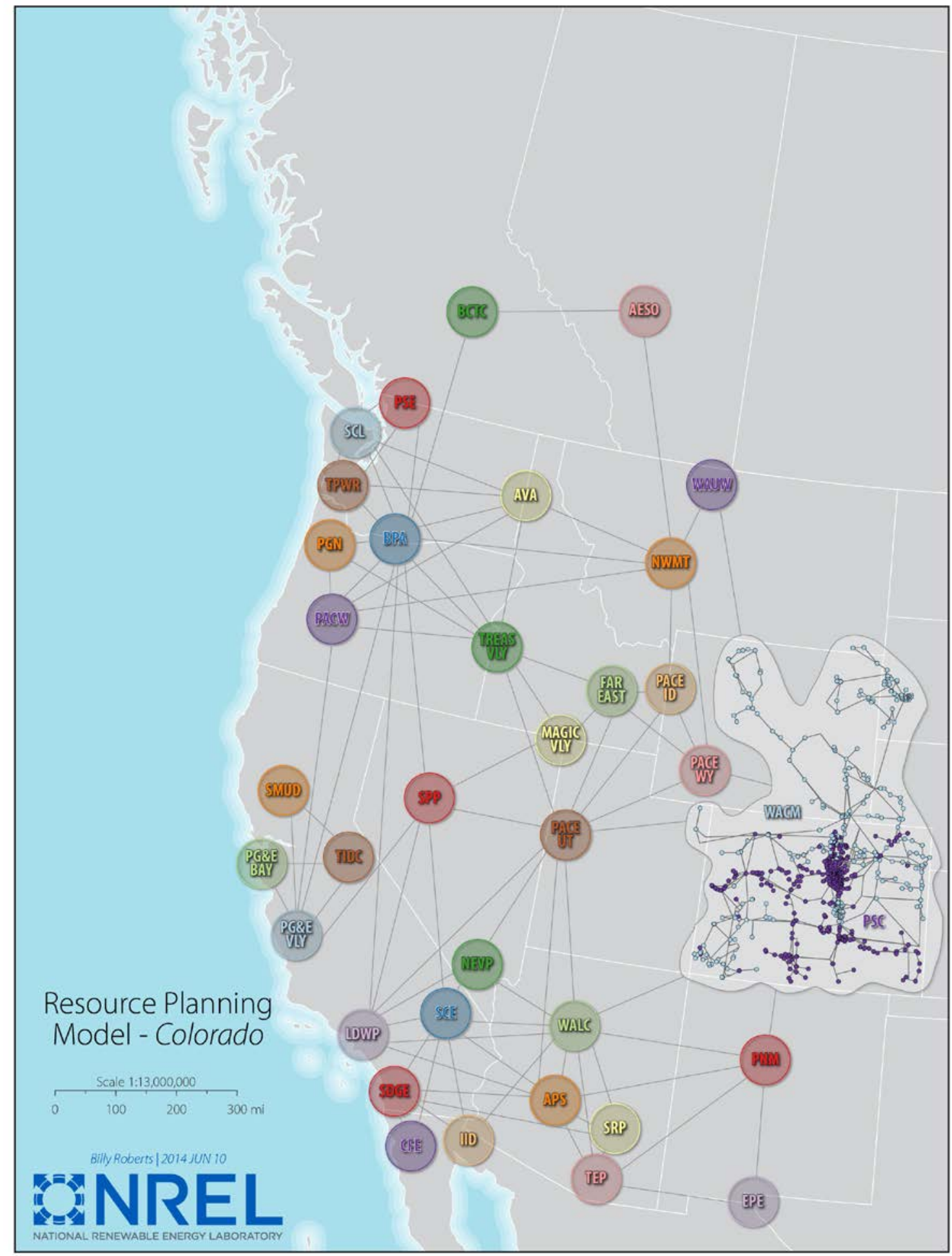

Figure 2. Combined zonal/nodal structure used for the CO-centric version of RPM 
Table 2. Start Year (2010) Capacity in the Resource Planning Model

\begin{tabular}{lrc}
\hline Generator Type & $\begin{array}{c}\text { PSCO and WACM Focus } \\
\text { Region (MW) }\end{array}$ & $\begin{array}{c}\text { Entire Western } \\
\text { Interconnection (MW) }\end{array}$ \\
\hline Coal & 7,331 & 38,529 \\
\hline Coal Cogeneration & 0 & 289 \\
\hline Natural Gas Combined Cycle (NG-CC) & 3,751 & 60,581 \\
\hline Natural Gas Combustion Turbine (NG-CT) & 3,423 & 20,139 \\
\hline Gas Cogeneration & 0 & 3,821 \\
\hline Gas Steam & 222 & 19,601 \\
Nuclear & 0 & 9,681 \\
\hline Biomass & 0 & 1,559 \\
Geothermal & 0 & 3,054 \\
\hline Hydropower - Fixed & 1,188 & 17,449 \\
Hydropower - Flexible & 5,879 & 58,437 \\
Pumped Hydropower Storage & 560 & 3,787 \\
\hline Solar Photovoltaic (PV) - Fixed-Tilt & 8 & 74 \\
\hline Solar PV - Single-Axis Tracking & 0 & 0 \\
Concentrating Solar Power (CSP) without & 0 & 428 \\
Thermal Energy Storage (TES) & 0 & 0 \\
\hline CSP with TES & 1,405 & 247,606 \\
\hline Wind & 23,768 & 0,171 \\
\hline Total & & \\
\hline
\end{tabular}

In addition to nodes and model BAs, RPM includes additional spatial layers to represent renewable resources. In particular, 100 solar and 100 wind resource regions are generated for each version of RPM as delineated by focus region to characterize the location-dependent nature of these renewable resources. To apply greater resolution to the $\mathrm{CO}$-centric focus region, the focus region contains 40 solar and 40 wind resource regions while the remaining 60 solar and 60 wind regions reside in the rest of the Western Interconnection. Resource potential (in $\mathrm{km}^{2}$ of land area), performance (annual and hourly capacity factors), and grid interconnection distances are used to characterize the solar or wind resources available for capacity expansion in each renewable region. ${ }^{16}$

Identical solar resource regions are used to represent all solar technologies modeled: fixed-tilt PV, single-axis tracking PV, CSP without TES, and CSP with TES. The regions are calculated by applying a Max-P clustering algorithm (Duque, Anselin, and Rey 2012) to PV fixed-tilt performance profiles produced by PVWatts for each 10-km gridded 8,760 hourly insolation time series for 2006 (NREL 2007). As with other clustering algorithms, Max-P clustering minimizes

\footnotetext{
${ }^{16}$ Multiple interconnection points (buses) are available to connect any individual wind or solar resource region. The specific interconnection point or points used is a model decision.
} 
intra-cluster, and maximizes inter-cluster, variations, and enforces cluster spatial continuity. Then for each PV and CSP technology, representative hourly profiles and annual capacity factors are generated from PVWatts and SAM (SAM 2015), respectively, based on the site within each cluster that has the closest capacity factor to the entire cluster. The left panel in Figure 3 shows the resulting distribution of the solar resource regions used for the CO-centric version of RPM.
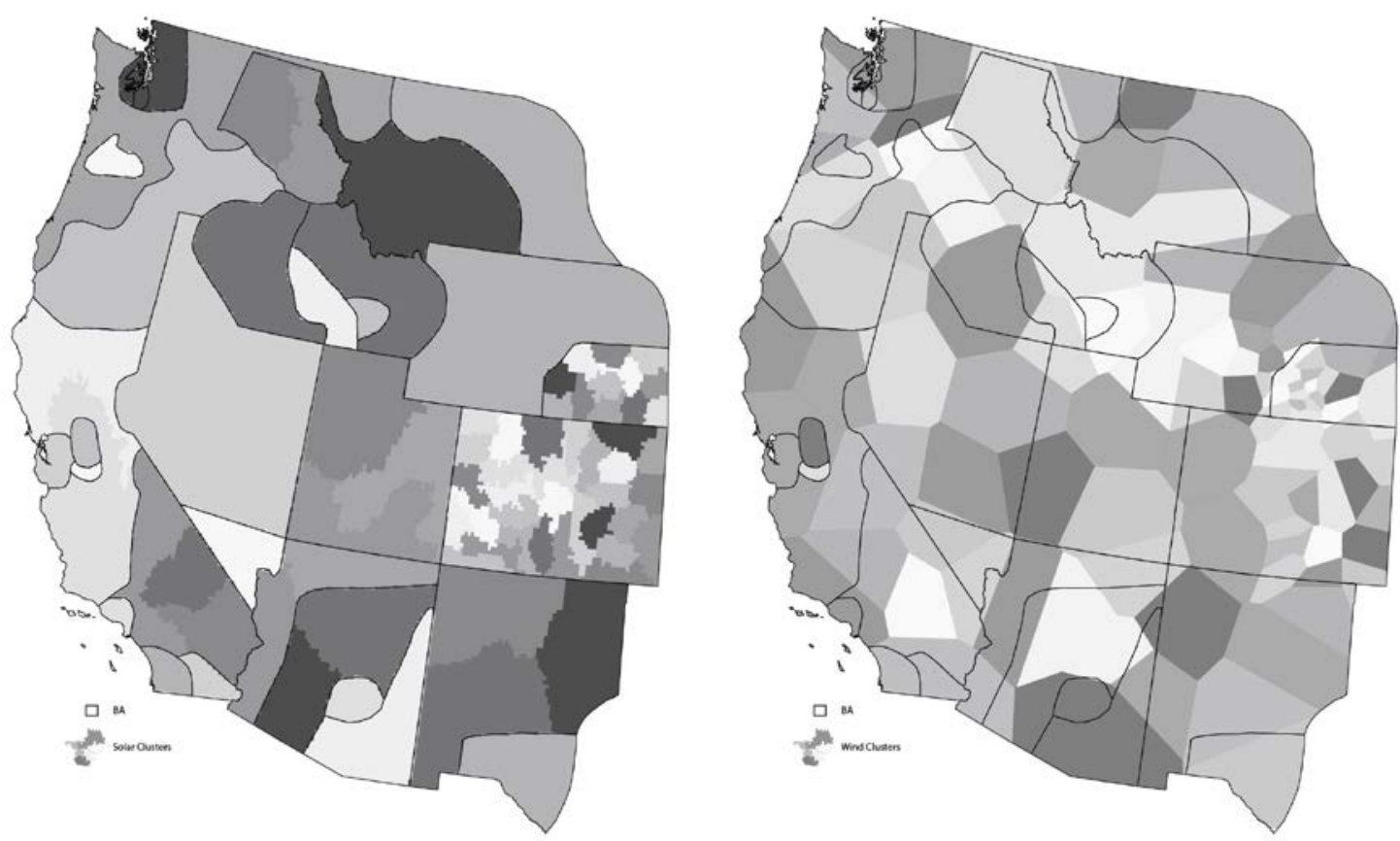

Figure 3. Solar (left) and wind (right) resource regions modeled in the CO-centric version of RPM for the U.S. portion of the Western Interconnection

A K-Means clustering algorithm (Macqueen 1967) is applied WWSIS site data ${ }^{17}$ (for 2006) site data to create the wind resource regions. However, because the wind resource data are based on site data and are not gridded, the spatial extents of the clusters are Voronoi polygons calculated to evenly divide the cluster centroids. The same wind clusters (Figure 3) are used for all five wind resource classes modeled. As with each solar technology, each wind class in each resource region is associated with a resource potential (in $\mathrm{km}^{2}$ of land area), performance (annual and hourly capacity factors), and grid interconnection distances. ${ }^{18}$ While any representation in a model necessitates simplifications, the clustering methods employed to aggregate locationdependent renewable resource data help reduce the amount of arbitrariness in region design. Further discussion of clustering renewable resource data can be found in Getman et al. (forthcoming).

\footnotetext{
${ }^{17}$ Each WWSIS site represents $30 \mathrm{MW}$ wind plant capacity potential. See http://www.nrel.gov/electricity/transmission/western_wind_disclaimer.html

${ }^{18}$ However, for wind the underlying annual capacity factors are not used as they are for solar. The hourly profiles are instead scaled to match annual capacity factor values shown in Table 3 or analogous data for 2010, see Section 2.4 for details.
} 
RPM is a sequential optimization model that starts in 2010 and ends in 2030, advancing in 5-year increments. For 2010, the optimal solution is based solely on dispatch and excludes any investment decisions. ${ }^{19}$ In other words, while the 2010 installed capacity reflects the infrastructure as represented in the model database from Lew et al. (2013), we allow RPM to dispatch that capacity subject to the dispatch constraints described in Section 2.3. The result of this dispatch and a comparison with historical dispatch is provided in the appendix. For all future solve years $(2015,2020,2025$, and 2030), new capacity investment decisions are considered in the model (see Section 2.4).

\subsection{Dispatch Modeling}

Dispatch modeling in the present version of RPM includes many of the same equations as the version described in Mai et al. (2013); differences are primarily a consequence of the different spatial structures. In particular, load balancing in the present version is constrained to occur for each hour at every node within the $\mathrm{CO}$-centric focus region and for every zone in the rest of the Western Interconnection. Power transfers are allowed between zones along existing connections and are constrained by interface limits from Lew et al. (2013). Intra-zonal transmission is not constrained except within the focus region, in which case transmission line-specific constraints are enforced as listed in the model database from Lew et al. (2013), according to one of three different user-selected configurations:

- DC Power Flow: Linearized DC power flow model governing power flow according to line-specific impedances and capacity ratings

- Pipe Flow: Transportation model allowing power to flow along any path subject to the line-specific capacity ratings

- Copper Plate: Line level transmission constraints are not enforced. ${ }^{20}$

Power transfers between the focus region and other zones are limited by both the interface limits and line-specific modeling, except in the "copper plate" configuration where line-specific ratings are relaxed. Hurdle rates from WECC (2014) are included in the model to represent friction in electricity transmission between BAs.

Within each solve year, the optimization algorithm considers four separate dispatch periods: Low, Mid, High, and Peak. Hourly time-steps are modeled within each dispatch period. K-Means clustering is used to identify the representative week for each of the non-peak dispatch periods. Each of the identified weeks are designed to represent multiple weeks and are scaled accordingly to inform annual values (e.g., annual generation, costs, and emissions); the Low, Mid, and High periods represent 34 weeks, 14 weeks, and 4 weeks, respectively. The weeks represented by each dispatch period are not necessarily adjacent; in other words, the 34 weeks in the Low period do not represent 34 continuous weeks but rather sample from multiple months and seasons of the calendar year. However, the Low period intuitively includes many weeks in the spring and

\footnotetext{
${ }^{19}$ For projects that either have been installed since 2010 or are in later stages of development, we exogenously include them in RPM. Similarly, retirements and announced retirements are exogenously considered as well. See Section 2.4 for details.

${ }^{20}$ For all transmission representations, including Copper Plate, inter-BA transmission is represented using a pipe flow model where transfers are constrained by interface limits from Lew et al. (2013).
} 
autumn and the High period mainly samples from the summer. Figure 4 illustrates the sampling of the representative dispatch weeks in RPM.

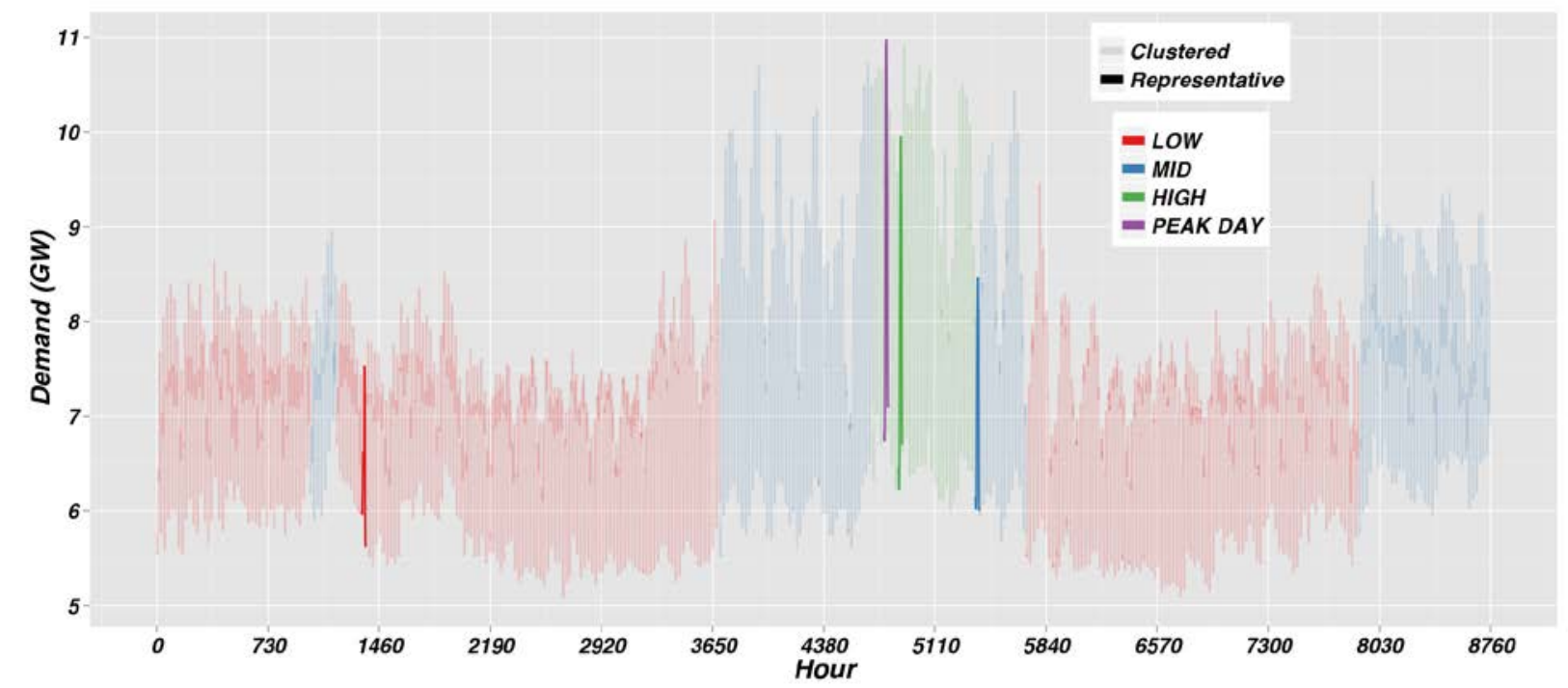

Figure 4. CO-centric focus region demand clustered in 'LOW', 'MID', 'HIGH', and 'PEAK DAY' periods

Representative weeks selected for dispatch modeling are highlighted.

The meteorological year for the study is 2006. In particular, as with our representation of the wind and solar resource, 2006 load data are used but scaled to match the annual load for historical (2010) and projected annual demands (2015-2030). ${ }^{21}$ Modeling coincident 2006 load, solar, and wind profiles enables RPM to capture hourly, diurnal, and seasonal effects simultaneously for power plant dispatch and investments. ${ }^{22}$ The 24-hour long peak dispatch period includes the peak demand hour for the focus region for the year. For each of the non-peak periods, up to four-day dispatch is modeled. ${ }^{23}$ The duration of the peak and non-peak dispatch periods can be selected by the modeler to match simulation needs. Additionally, an "average day" configuration is available to simulate 24 hours for each of the peak and off-peak dispatch periods. In the average day configuration, the hourly wind, solar and load profiles are averaged for each day of the representative weeks (i.e., seven samples of each hour of the day are averaged together to form the "average day" profiles). While further work is needed to evaluate the choice

\footnotetext{
${ }^{21}$ Wind and solar profiles are scaled to match assumed annual available energy production, including regionspecific characteristics and any effects of assumed technology improvements (see Section 2.4 for assumed annual capacity factors for different wind groups), while maintaining the profiles from the identified weeks used. This scaling can lead to hourly output that exceeds the nameplate capacity; however, these occurrences are rare and have little impact on resource selection results.

${ }^{22}$ Future model improvements include the use of multiple meteorological years for more robust representation of long-term resource characterizations.

${ }^{23}$ In total, the longest dispatch periods evaluated in our analysis result in 408 dispatch hours per model year: 96 hours per non-peak dispatch period times 3 non-peak dispatch periods plus 24 hours per peak day.
} 
of hours and dispatch periods to model, ${ }^{24}$ the time resolution in RPM is generally aligned with or improved from many other CEMs (Sullivan, Eurek, and Margolis 2014).

Security-constrained economic dispatch, where energy and operating reserves are co-optimized, is modeled. We model three separate categories of operating reserves representing requirements over a range of timescales: regulation reserves (sub-5 minute), spinning contingency reserves (10 minutes), and flexibility reserves (60 minutes). All operating reserves are required to be met within 20 assumed reserve-sharing groups in the Western Interconnection. ${ }^{25}$ Regulation reserve requirements are assumed to be $1 \%$ of demand for all regions. ${ }^{26}$ Spinning reserve requirements are assumed to be $3 \%$ of demand for all reserve sharing groups outside of the focus region. The Colorado reserve-sharing group includes the PSC and WACM BAs, and the spinning reserve requirement is based on the shared single largest contingency. The requirement is split between the two BAs such that the contingency requirements for PSC and WACM are 451 MW and 359 MW, respectively, half of which must be spinning. We assume flexibility reserve requirements that depend on wind and solar deployment, loosely based on results from Lew et al. (2013). ${ }^{27}$ More specifically, we assume $10 \%$ and $7.5 \%$ of instantaneous wind and solar penetration, respectively, for the flexibility reserve requirement, which must be met by spinning resources. ${ }^{28}$ We model "up" reserves only for computational tractability and because they are typically more expensive to procure than "down" reserves. ${ }^{29}$ For the same reasons, we also exclude non-spin reserve requirements in the model. Constraints are applied to limit the provision of reserves based on unit-specific ramp rates, timescale of the reserve requirements, unit commitment status, and available capacity. ${ }^{30}$

We include constraint configurations that model limits to both unit commitment and dispatch of thermal power plants. Many of the constraints are similar to those from the dispatch model used in Sioshansi and Denholm (2010) and include minimum on and off periods, minimum generation points, start-up costs, ramping limits, and outage rates. ${ }^{31}$ To reduce the number model variables, we do not include heat rate curves and instead use the full-load heat rate independent of plant. Parameters directly from Lew et al. (2013) modeling data are used for existing thermal power

\footnotetext{
${ }^{24}$ See De Sisternes et al. (2013) for an example of recent work on sampling weeks for generation planning models. The method employed in RPM is similar to the method presented by Nahmmacher et al. (2014).

${ }^{25}$ Reserve sharing groups are identical to those from Lew et al. (2013).

${ }^{26}$ Regulation reserve requirements can increase with wind and solar penetration (Lew et al. 2013); however, we do not include this typically small dependency in RPM.

${ }^{27}$ Flexibility reserve requirements have not been widely adopted and have little impact on model results due to the longer timescales associated with these requirements. Nonetheless, we include them in RPM because they are being considered to help manage renewable grid integration (Hummon et al. 2013).

${ }^{28}$ The simple method for flexibility reserves that we apply differs from the methods used by Lew et al. (2013). As discussed in Section 5, we find that operating reserves have little effect on capacity expansion results.

${ }^{29}$ At higher renewable penetration values than modeled for this report, downward flexibility may grow in importance.

${ }^{30}$ For example, a $100-\mathrm{MW}$ unit with a ramp rate of $1 \%$ (of nameplate capacity) per minute can provide up to $5 \mathrm{MW}$ to regulation reserves (based on the 5-minute timescale for regulation) if it is online, its energy dispatch level is less than $95 \mathrm{MW}$, and it is not offering any other operating reserve capacity.

${ }^{31}$ As we only model a subset of hours in a year, outage hours or days are not randomly or otherwise assigned. Instead, the effects of outages are represented through a limit on a plant's annual capacity factor. This method will likely lead to underestimate of system capacity needs; however, planning reserve requirements will mitigate these underestimates.
} 
plants. Parameters for new units are described in Section 2.4. For computational tractability, we model only a subset of generator types with unit commitment decisions in select model configuration settings ${ }^{32}$. This subset includes nuclear, NG-CC and coal (including co-fire) generators inside the focus region as well as large coal (>500 MW) and nuclear units outside of the focus region. Other units (or all units, when that model option is selected) are modeled linearly, that is, assumed always online and without minimum generation constraints.

The above treatment applies to thermal and nuclear power plants. Wind, solar, and hydropower plants are modeled differently, wherein most of these technologies are modeled to have a fixed profile depending on their location. Output profiles for wind and solar are discussed in Section 2.2. ${ }^{33}$ Similarly, fixed dispatch hydropower is modeled with the dispatch profiles assumed by Lew et al. (2013). For dispatchable hydropower units, operational constraints are set by minimum and maximum operating points and monthly energy limits. Because four days is the longest period considered in the model, the monthly energy minimum and maximum constraints are decomposed by the fraction of the month represented by the hours in each dispatch period. The result is dispatch period-dependent minimum and maximum energy constraints. Storage dispatch is also modeled endogenously where charging/discharging profiles are model decisions. Over every dispatch period, the ratio between the amount of storage charging and discharging is fixed based on assumed round trip efficiencies. ${ }^{34}$ We do not model new storage investments in the present version of the model.

We model curtailment of variable generation technologies as a decision-variable within the model. We do not allow curtailed variable generation to provide reserves (Ela et al. 2014) in the current version of RPM and recognize that this representation potentially undervalues investments in new variable generation. Estimated renewable curtailment is small in the scenarios presented in this report and, thus, this representation likely has little impact on results. Nonetheless, future research is needed to evaluate the impact that allowing variable generation to provide operating reserves might have on resource selection.

\subsection{Investment Decision Assumptions and Drivers}

Investment decisions in RPM are made simultaneously with the dispatch modeling described in Section 2.3. In this section, we briefly describe the model treatment of certain topics that directly influence investment decisions, and we provide the key assumptions used in our analysis for the key technologies relevant to our analysis, including natural gas-fired, wind, and solar PV technologies. ${ }^{35}$ The restriction to these technologies is for analytic simplicity only and should not be interpreted as projections or expectations for technology deployment in the future. These assumptions are intended to demonstrate the model capability and only support the analysis around model structure.

\footnotetext{
${ }^{32}$ For computational tractability, scenarios that consider unit commitment are not included in the present analysis.

${ }^{33}$ CSP profiles are generated from the System Advisor Model (sam.nrel.gov) using 2006 weather files for the solar regions described in Section 2.2. While CSP with TES has greater dispatch flexibility than modeled, the current version of RPM simply uses the hourly dispatch profiles from the System Advisor Model.

${ }^{34} \mathrm{We}$ assume a round trip efficiency of $80 \%$ for all pumped storage hydropower plants.

${ }^{35}$ RPM includes many other technologies as shown in Table 2, some of which may play important roles in the future. Nonetheless, our analysis is restricted to new natural gas-fired, wind, and solar PV technologies.
} 
Table 3 shows the assumed technology costs and performance used in our analysis. Data for natural gas-fired technologies are consistent with those found in the National Renewable Energy Laboratory's Annual Technology Baseline (NREL 2015), which relies on data from the Annual Energy Outlook 2014 Reference scenario (EIA 2014) for natural gas-fired technologies, DOE reports (DOE 2012) for solar technologies, and internal analysis for wind technologies. The overnight capital costs shown in Table 3 include costs of all equipment up to the plant gate and do not include the spur line and financing costs, which are included separately in the model. ${ }^{36}$ Spur line costs for new renewable capacity vary between resource regions and depend on the distance between the centroid of the wind or solar resource region and the connected bus. RPM also includes financing costs (Short et al. 2011) that vary between technologies to account for differences in construction periods, accelerated tax depreciation rules, and investment tax credits. ${ }^{37}$

Other parameters that characterize new natural gas-fired plants include minimum plant size, minimum generation points, ramp rates, and siting options. In RPM, we have the option to restrict new NG-CC units to be at least $450 \mathrm{MW}$. No lower limits are applied to NG-CT, wind and solar plants, as these technologies are more modular and are less influenced by economies of scale than their counterparts are. We assume new NG-CC and NG-CT capacity to have maximum ramp rates of $0.8 \%$ and $10 \%$ of nameplate capacity per minute, respectively. Minimum generation points for all new natural gas-fired generators are assumed to be zero to allow for linear dispatch and improve model tractability.

Assumed fuel costs are shown in Figure 5 and are based on national fuel projections from the AEO 2014 Reference scenario (EIA 2014). Fuel costs are assumed to be uniform across regions and without seasonal or diurnal variations within each solve year. While volatility and uncertainty exists for fuel prices, particularly for natural gas, fuel sensitivities are not included in our analysis. We do not include foresight, such as for fuel price forecasts, in RPM.

\footnotetext{
${ }^{36}$ Real 2010 dollars are used throughout this report unless otherwise noted.

${ }^{37}$ Technology-specific financing costs are represented in RPM through different fixed charge rates that capture different tax and construction period considerations for different technologies. Fixed charge rates for NG-CC, NGCT, wind, and solar PV are 0.126, 0.120, 0.105, and 0.091, respectively, for all years with the exception of a fixed charge rate of 0.065 for solar PV in 2015 to represent the $30 \%$ investment tax credit available before 2017 . These fixed charge rates are used to calculate amortized capital over 20 years using a nominal weighted average cost of capital of $8.9 \%$.
} 
Table 3. Technology Cost and Performance Assumptions for New Generation Capacity

\begin{tabular}{|c|c|c|c|c|}
\hline & 2015 & 2020 & 2025 & 2030 \\
\hline \multicolumn{5}{|c|}{ Overnight Capital Costs $(2010 \$ / k W)$} \\
\hline NG-CC & 940 & 890 & 870 & 850 \\
\hline NG-CT & 780 & 750 & 730 & 720 \\
\hline Wind (best resource bin) & 1,520 & 1,470 & 1,440 & 1,420 \\
\hline Wind (worst resource bin) & 1,640 & 1,630 & 1,620 & 1,610 \\
\hline PV Fixed-Tilt & 2,190 & 1,500 & 1,380 & 1,250 \\
\hline PV Single-Axis Tracking & 2,250 & 1,640 & 1,520 & 1,390 \\
\hline \multicolumn{5}{|l|}{ Fixed O\&M (2010\$/kW-yr) } \\
\hline NG-CC & 14 & 14 & 14 & 14 \\
\hline NG-CT & 7 & 7 & 7 & 7 \\
\hline Wind (all bins) & 47 & 46 & 45 & 44 \\
\hline PV (all) & 15 & 7 & 7 & 7 \\
\hline \multicolumn{5}{|l|}{ Variable O\&M (2010\$/MWh) } \\
\hline NG-CC & 3 & 3 & 3 & 3 \\
\hline NG-CT & 12 & 12 & 12 & 12 \\
\hline Wind (all bins) & 0 & 0 & 0 & 0 \\
\hline PV (all) & 0 & 0 & 0 & 0 \\
\hline \multicolumn{5}{|l|}{ Heat Rate (MMBtu/MWh) } \\
\hline NG-CC & 6.68 & 6.62 & 6.57 & 6.57 \\
\hline NG-CT & 10.0 & 9.76 & 9.50 & 9.50 \\
\hline \multicolumn{5}{|l|}{ Capacity Factor (\%) } \\
\hline Wind (best resource bin) & $52 \%$ & $54 \%$ & $55 \%$ & $56 \%$ \\
\hline Wind (worst resource bin) & $33 \%$ & $35 \%$ & $36 \%$ & $37 \%$ \\
\hline PV Fixed-Tilt & $13-22 \%$ & $13-22 \%$ & $13-22 \%$ & $13-22 \%$ \\
\hline PV Single-Axis Tracking & $15-27 \%$ & $15-27 \%$ & $15-27 \%$ & $15-27 \%$ \\
\hline
\end{tabular}

Note: PV capacity is represented in DC terms. PV capacity factor reflects AC output over DC capacity. $A C$ capacity and output are used for all other technologies. 


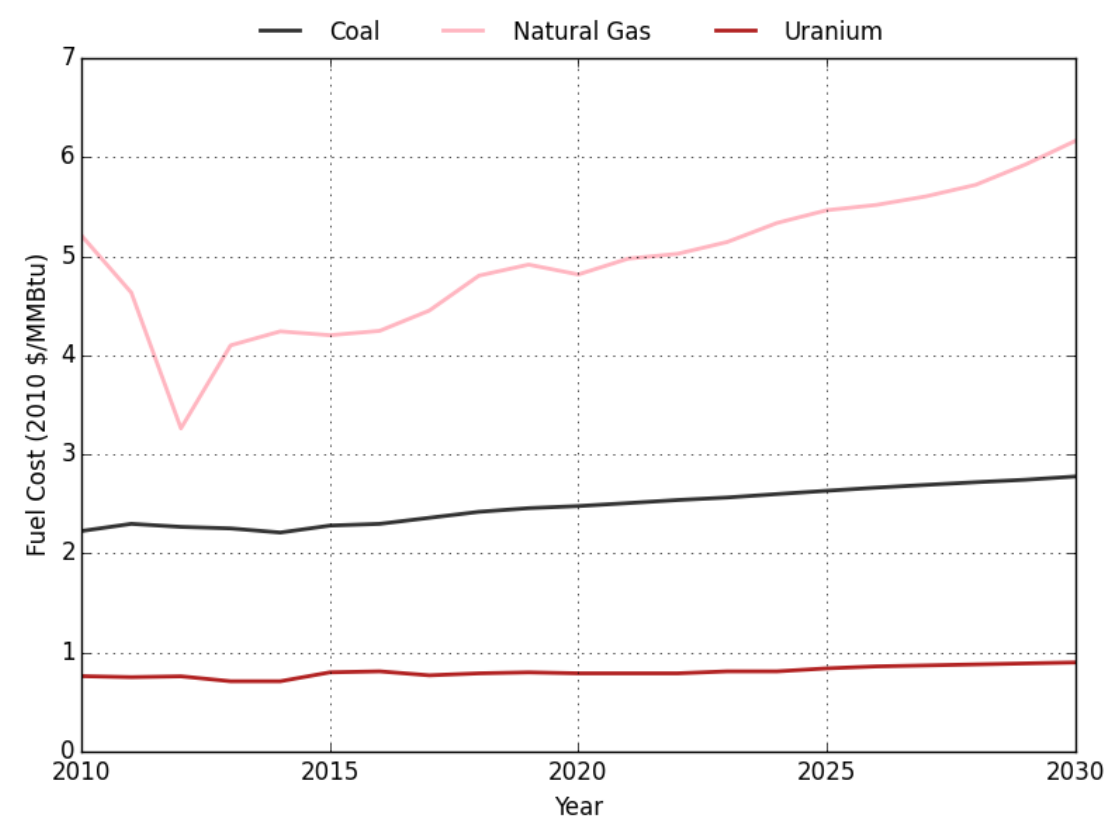

Figure 5. Assumed natural gas, coal, and uranium prices from 2010 to 2030 (EIA 2014)

New solar capacity deployment is restricted by the technical potential of the resource in each resource region. The technical potential assessment uses the same methodology and exclusions as in Lopez et al. (2012). More specifically, solar resource is based on 10-km satellite modeled data set from NREL (2007). New wind capacity deployment is restricted to $30 \mathrm{MW}$ of potential per WWSIS site per wind resource class. No such resource limits are applied to new natural gas capacity or utilization; however, we assume that any new natural gas-fired generation capacity will be constructed at locations (electrical busses) where existing natural gas-fired capacity is already connected to limit model decision variables. We do not model natural gas or any other fuel infrastructure (e.g., pipelines and storage) in RPM.

The primary factors, beyond fuel and technology costs, that drive RPM's investment decisions relate to demand growth, planning reserves, and state renewable portfolio standard (RPS) requirements. We assume constant demand growth rates for each BA and we calculate them using the average of estimated annual load growth between 2010 and 2016 in WECC (2014a). As a result, the interconnection-wide annual load growth rate between 2010 and 2030 is $0.9 \%$ per year with some BAs having lower, including negative, growth rates. ${ }^{38}$ Hourly demand profiles are assumed to be the same for all years and based on 2006 profiles.

Planning reserve constraints are applied to ensure North American Electric Reliability Corporation (NERC) resource adequacy requirements (NERC 2013) are met. We set a planning reserve requirement for each of four NERC sub-regions ${ }^{39}$ in the Western Interconnection to be the peak demand in that region plus a reserve margin. NERC reference reserve margin levels for

\footnotetext{
${ }^{38}$ While different demand projections are offered through the IRP reports, these have not been implemented in RPM.

${ }^{39}$ The regions are WECC-CAMX, WECC-NWPP, WECC-RMRG, and WECC-SRSG.
} 
the four sub-regions range from $13.56 \%$ to $15.02 \%$ of peak demand (NERC 2013). ${ }^{40}$ All nonvariable generators are assumed to contribute their full nameplate capacity to the planning reserve requirement; a capacity credit of one is assumed for all thermal capacity, hydropower, CSP with TES, and storage. For variable generation, including wind, solar PV, and CSP without TES, we endogenously estimate the capacity credit using a capacity factor-based approximation method similar to the method described in Mai et al. (2013). ${ }^{41}$ The method relies on the full 8,760 load, solar, wind, and hydropower profiles to estimate the impact of existing and potential new capacity on the peak net load. The method accounts for the contribution of variable generation during peak hours and the potential shift in occurrence of the peak net load. Estimated capacity credits are updated between solve periods, and they depend on load growth and investment decisions made during the prior solve period. Marginal capacity credits vary by location and technology (e.g., wind versus solar PV, single-axis tracking PV versus fixed-tilt PV, different wind classes, PV from one resource region versus another).

Existing state RPSs are modeled in RPM based on data from DSIRE. ${ }^{42}$ The RPS requirements are applied for each BA, and they depend on where the load served by each BA is located. For example, a BA that serves half of its load in a state with a $20 \%$ RPS and the other half in states without RPS policies will have an obligation to serve $10 \%$ (half of $20 \%$ ) of its end-use demand from qualifying renewable sources. We include technology-specific requirements such as solar carve outs. Credit trading for RPS compliance is not modeled in the scenarios presented. While we attempt to represent the general effects of RPSs on investment decisions, further work is needed to more rigorously apply RPS rules and incentives in the model, including trading rules and existing contracts from out-of-state projects that qualify for RPS compliance. For this reason, the results presented in Sections 4 and 5 imperfectly reflect RPS or other policy-driven decisions. In addition, the present version of RPM does not include a representation of state carbon cap and trade systems (e.g. California Assembly Bill 32) or other state- or localincentives. We include current federal tax credit legislation for wind and solar, including an absence of the wind production tax credit for 2015-2030 and a changing investment tax credit that drops from $30 \%$ to $10 \%$ after 2016 for commercial and utility-scale solar.

Recent (2010-2014) and expected new capacity additions are exogenously included in RPM based on data from Ventyx (2010) and SolarPaces (2014). These include 17.5 gigawatts (GW) between 2011 and 2016 of primarily new natural gas and wind capacity. ${ }^{43}$ In addition, expected plant retirements are exogenously applied based on Saha (2013) for near-term coal plant

\footnotetext{
${ }^{40}$ For the WECC-CAMX region, we assume 11,000 MW and 5,000 MW of capacity are available from the NWPP and SRSG sub-regions, respectively, to meet planning reserve requirements for all years. We assume that the deductions from NWPP and SRSG are not available to supply capacity reserves in their respective regions. This representation follows the Maximum Import Capacity considered by the California Independent System Operator. Planning reserve requirements are met by local resources only for the other three sub-regions.

${ }^{41}$ While the method in Mai et al. (2013) only considered the single peak net load hour, our method averages the capacity credit estimate using the top 100 peak net load hours for solar and wind technologies.

42 See www.dsireusa.org/.

${ }^{43}$ Planned capacity additions total 6.6 GW for wind, 5.7 GW for natural gas, 2.6 GW for PV, 1.9 GW for CSP, 0.4 $\mathrm{GW}$ for coal, $0.1 \mathrm{GW}$ for hydropower, and $0.1 \mathrm{GW}$ for biomass. These numbers reflect those from the data sources used and underestimate the amount of new capacity that has either been installed since 2010 or is under construction. However, additional new capacity beyond these values is deployed in RPM as a part of the model's decision making process.
} 
retirements and Lew et al. (2013) for other retirements. We supplement these retirements by including the 2012 San Onofre Nuclear Generating Station retirement, and we assume that one unit of the Navajo Generating Station is retired in 2020 (Hurbut et al. 2012). In total, we assume nearly $26 \mathrm{GW}$ of capacity retirements between 2010 and 2030, with most retired by $2020{ }^{44}$ The optimization in RPM does not explicitly consider any other retirements, such as economic retirements.

Transmission expansion is allowed along existing transmission corridors and for spur line connections to new wind and solar generation. That is, aside from new wind and solar connections, transmission expansion is only allowed between already connected nodes for the present analysis. Transmission expansion costs are assumed to be $\$ 835 / \mathrm{MW} / \mathrm{km}$ for expansion of existing lines and $\$ 2,274 / \mathrm{MW} / \mathrm{km}$ for spur line connections to new wind and solar capacity (EIPC 2012). ${ }^{45}$ Model configurations either enable the restriction of transmission expansions to Western Interconnection-wide, focus-region only expansion or provide for no transmission expansion. Regardless of configuration, spur line expansions are estimated only for connections to new wind and solar capacity.

\footnotetext{
${ }^{44}$ Retirements total $15 \mathrm{GW}$ for gas steam, $6.75 \mathrm{GW}$ for coal, $2.2 \mathrm{GW}$ for nuclear, and $1.9 \mathrm{GW}$ for natural gas.

${ }^{45}$ Transmission costs can vary tremendously between sites and across transmission technologies. For example, assumed transmission costs are based on new lines and not based on lower cost options, such as re-conductoring. Further work is needed to evaluate how results may change under different assumptions.
} 


\section{Scenario Framework}

To assess the importance of model configuration on scenario results, we model and compare a range of scenarios that include different model representations of capacity credit, system operations, and transmission. We start with a Reference (REF) scenario that uses the key assumptions described in Section 2 and a version of RPM set with the following configurations:

- Endogenous and dynamic estimations for capacity credit using a net peak load approximation method

- Co-optimization for load-balancing and operating reserves

- All linear variables (no minimum unit sizes, minimum generation points, start-up costs, or minimum on/off periods)

- Average day dispatch periods;

- Co-optimization of generation and transmission expansion

- Pipe-flow model for power flows with hurdle rates between BAs.

We model 10 sensitivity scenarios using different configurations of RPM (see Table 4). In contrast to a traditional sensitivity analysis in which a range of input parameters is analyzed, we use identical input assumptions across all scenarios, and instead modify the model treatment of capacity credit, dispatch modeling, and transmission modeling. Some of the model configurations used to develop the sensitivity scenarios are designed to include more detail than the REF scenario, whereas others represent simplified variants of the model configuration used for the REF scenario. Due to computational tractability issues, none of the modeled scenarios utilize the full capabilities of RPM. The overall goal of the sensitivity analysis is to understand the impacts that different model configurations have on scenario results. None of the scenarios is intended to be a prediction of the future, and we acknowledge that the highly uncertain input parameters can significantly drive model results, perhaps in greater magnitude than differences in model configuration. Nonetheless, our analysis provides insights into the importance of various model structures under a narrow set of conditions. By making comparisons using a single modeling framework, we can quantify the effects self-consistently. ${ }^{46}$

The issues raised in Section 1 drive the specific motivations behind each individual sensitivity scenario. In particular, the capacity credit treatment variants reflect the common practice of optimizing the fleet without renewables prior to inserting renewable capacity as mandated (e.g., by RPS requirements) or by assigning a non-dynamic capacity credit. The dispatch modeling variants reflect the fact that some models adopt a simplified representation of power systems operation or lack co-optimization of energy and operating reserves. The transmission sensitivity scenarios reflect the common separation of generation expansion and transmission expansion planning or limited coordination between boundary regions. We also evaluate the computational trade-offs across the various model configurations.

\footnotetext{
${ }^{46}$ Multi-model comparisons are commonly conducted (e.g., Mignone et al. 2013) using synchronized data sets. However, because different models have intrinsically different data needs, isolating the model treatment from the data inputs is often not possible.
} 
Table 4. Scenario Framework and Definitions

\begin{tabular}{|c|c|c|c|}
\hline Scenario & Capacity Credit & Dispatch Modeling & Transmission \\
\hline Reference (REF) & $\begin{array}{l}\text { Endogenous and } \\
\text { dynamic capacity credit } \\
\text { calculations }\end{array}$ & $\begin{array}{l}\text { All linear variables } \\
\text { Co-optimization for } \\
\text { load-balancing and } \\
\text { operating reserves } \\
\text { Average day dispatch } \\
\text { period representation }\end{array}$ & $\begin{array}{l}\text { Co-optimization of } \\
\text { generation and } \\
\text { transmission expansion } \\
\text { Pipe-flow power flow } \\
\text { model }\end{array}$ \\
\hline $\begin{array}{l}\text { Capacity Credit } 0 \\
\text { (CCO) }\end{array}$ & $\begin{array}{l}\text { Zero average and } \\
\text { marginal capacity credit } \\
\text { for wind and solar PV }\end{array}$ & Same as REF & Same as REF \\
\hline $\begin{array}{l}\text { No Operating } \\
\text { Reserves (NOR) }\end{array}$ & Same as REF & $\begin{array}{l}\text { Operating reserve } \\
\text { requirements ignored }\end{array}$ & Same as REF \\
\hline One Day (1DAY) & Same as REF & $\begin{array}{l}\text { Single day operations } \\
\text { from } 24 \text { chronological } \\
\text { hours }\end{array}$ & Same as REF \\
\hline Four Day (4DAY) & Same as REF & $\begin{array}{l}\text { Four day operations } \\
\text { from } 96 \text { chronological } \\
\text { hours }\end{array}$ & Same as REF \\
\hline Must Run (MR) & Same as REF & $\begin{array}{l}\text { All large (>300 MW) } \\
\text { coal-fired and nuclear } \\
\text { units are set as must- } \\
\text { run (committed at or } \\
\text { above minimum } \\
\text { generation levels) }\end{array}$ & Same as REF \\
\hline $\begin{array}{l}\text { DC Power Flow } \\
\text { (DCOPF) }\end{array}$ & Same as REF & Same as REF & $\begin{array}{l}\text { Linearized DC power } \\
\text { flow model (DCOPF) }\end{array}$ \\
\hline Copper Plate (CP) & Same as REF & Same as REF & $\begin{array}{l}\text { Copper plate } \\
\text { transmission model (no } \\
\text { binding transmission } \\
\text { constraints) }\end{array}$ \\
\hline $\begin{array}{l}\text { Three Connection } \\
\text { (3CON) }\end{array}$ & Same as REF & Same as REF & $\begin{array}{l}\text { New renewable } \\
\text { generation can connect } \\
\text { to any of the } 3 \text { closest } \\
\text { nodes }\end{array}$ \\
\hline $\begin{array}{l}\text { Free Connection } \\
\text { (FCON) }\end{array}$ & Same as REF & Same as REF & $\begin{array}{l}\text { New renewable } \\
\text { generation can connect } \\
\text { to the closest node, but } \\
\text { incurs no cost } \\
\text { associated with spur } \\
\text { line construction }\end{array}$ \\
\hline $\begin{array}{l}\text { Islanded Focus } \\
\text { Region (IFR) }\end{array}$ & Same as REF & Same as REF & $\begin{array}{l}\text { High cost }(+\$ 1000 / \mathrm{MWh} \\
\text { hurdle rate) energy } \\
\text { transfers between the } \\
\text { focus region BAs and } \\
\text { the rest of the Western } \\
\text { Interconnection }\end{array}$ \\
\hline
\end{tabular}


The REF and sensitivity scenarios represent futures in which no new policies are enacted and current policies are modeled as they are legislated as of January 1, 2014. In particular, we assume state RPSs at their current levels (e.g., $30 \%$ by 2020 for Colorado), current tax incentives (e.g., no wind production tax credit after 2013, a solar investment tax credit of $30 \%$ dropping to 10\% after 2016), Modified Accelerated Cost Recovery System (MACRS) depreciation rules (e.g., 5-year MACRS for non-hydropower renewables), and other policies and subsidies embedded in the data inputs used in the model. ${ }^{47}$ Proposed rules or legislation are not included in any of the scenarios. The key data assumptions used for the scenarios are described in Section 2. The data assumptions and policy representation do not reflect predictions or recommendations. Instead, they are simply used to demonstrate model functionality and to isolate the effects of different model structures. It is important to note that our analysis is directed toward a set of "current policy" scenarios only. The applicability of the results under qualitatively different futures (e.g., scenarios with higher shares of renewable penetration) will require further investigation. Section 4 describes the results of the REF configuration scenario in detail. Section 5 presents the results of the sensitivity scenarios, focusing on their key differences with the REF scenario.

\footnotetext{
${ }^{47}$ The current version of RPM does not include a representation of California AB32. While this is an important omission for California results, our analysis focuses on Colorado and its neighbors; therefore, this omission has a more limited impact. And because our analysis focuses on incremental changes between scenarios, the effect is further minimized. Future work is needed to determine the degree to which AB32 may change findings from our analysis, particularly as it may increase renewable penetration levels in the Western Interconnection.
} 


\section{Reference Scenario Results}

This section presents results from the Reference (REF) scenario, which represents the baseline to which all other sensitivity scenarios are compared. The input assumptions and model configurations used for each scenario, including REF, are described in Sections 2 and 3. Specifically, the REF scenario employs the dynamic capacity credit estimates, "average day" per dispatch period representation, "pipe-flow" transmission representation, and "linearized" unit commitment representation. As described in Section 3, none of the scenarios, including the REF scenario, is intended to be a prediction or forecast of the future power system in the Western Interconnection.

\subsection{Capacity Expansion}

Figure 6 presents the Western Interconnection-wide annual generation (right) and capacity expansion (left) results for the REF scenario. Changes in installed capacity reflect plant retirements (see Section 2.4 for retirement assumptions) and new capacity investments. Figure 6 shows the net combined effect. Significant capacity growth is only observed for wind and solar technologies in the REF scenario. Under the conditions modeled, wind capacity reaches 22,230 MW by 2020 and 29,671 MW by 2030. Solar capacity growth is similar, reaching 42,700 MW and 49,112 MW by the same years, respectively. In comparison, 2010 wind and solar capacity in the Western Interconnection totals 10,171 MW and $503 \mathrm{MW}$, respectively. On an annual generation basis, combined solar and wind penetration approaches $18 \%$ by 2020 and $20 \%$ by 2030 for the Western Interconnection.

Annual generation and capacity expansion results for the $\mathrm{CO}$-centric focus region are presented in Figure 7. Compared to the interconnection-wide results in Figure 6, the focus region is more heavily coal- and wind-reliant, but combined wind and solar penetrations are similar (24\% by 2030). Installed wind and solar capacity in 2030 reach 4,300 MW and $614 \mathrm{MW}$, respectively, compared with 1,405 MW and $8 \mathrm{MW}$ in 2010.
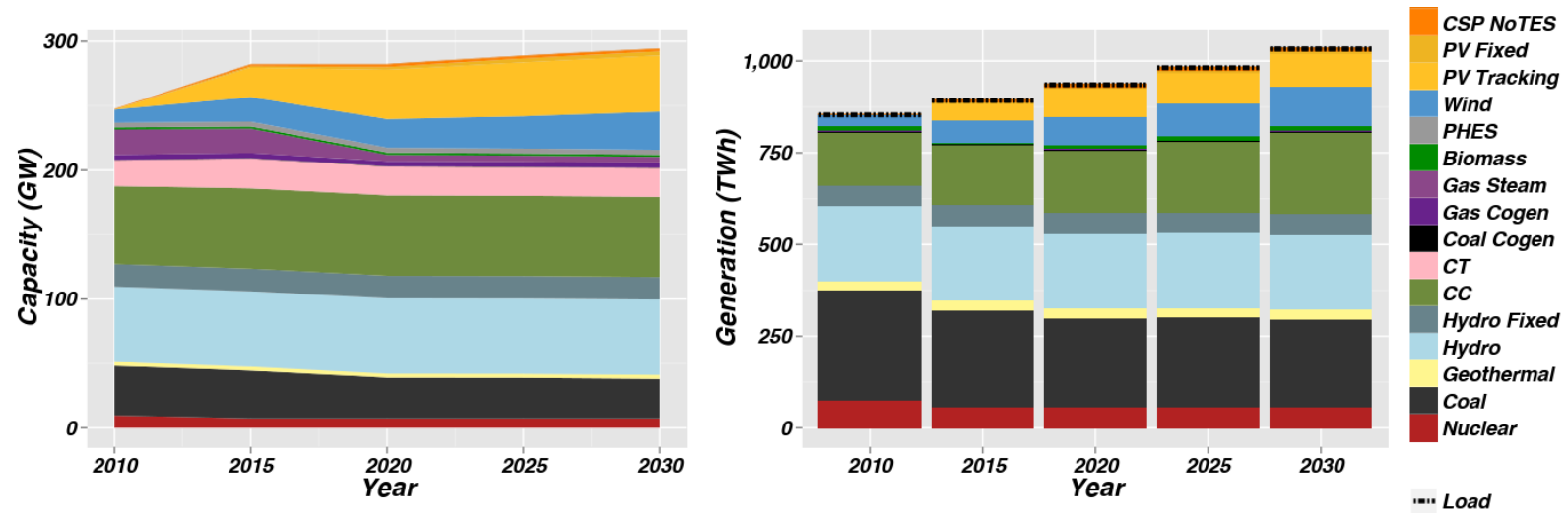

Figure 6. Western Interconnection installed capacity (left) and annual generation (right) from 2010 to 2030 in the REF scenario 

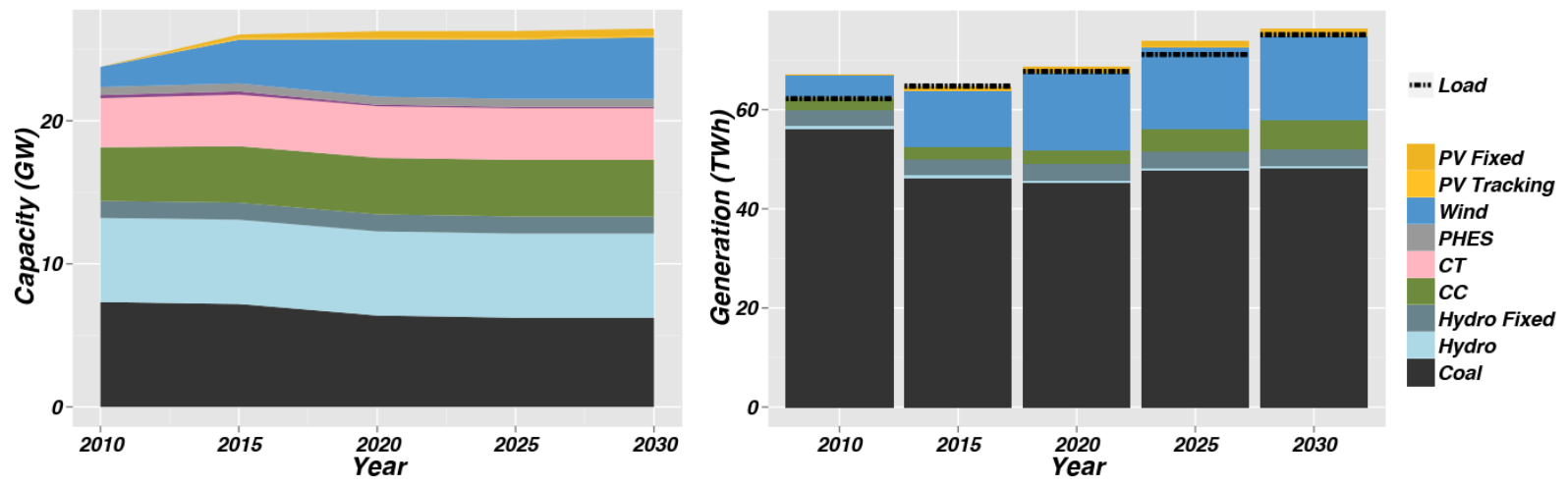

Figure 7. CO-centric focus region installed capacity (left) and annual generation (right) from 2010 to 2030 in the REF scenario

Existing RPS policies are the primary drivers of the increased renewable capacity deployment found in the REF scenario. RPS constraints are largely binding in nearly all BAs that serve loads in states with existing RPS requirements. One notable exception is the PSC BA, where a flat RPS requirement between 2020 and 2030 (30\% for Colorado), and declining load growth assumptions result in no RPS-driven demand for new renewable capacity growth after 2020. Understanding the implications of the model configuration sensitivity analysis (Section 5) requires recognizing the drivers of new capacity growth, including whether the RPS constraint is binding. The prominent role that RPS has in the REF scenario highlights that our analysis only explores renewable penetration levels driven by these policy targets; some of the model features explored may play more critical roles at higher solar or wind penetration levels.

From 2010 to 2030, there is a net reduction of 7,919 MW in coal-fired capacity (from 38,818 MW to $30,899 \mathrm{MW}$ ) that is entirely a result of our exogenous retirement assumptions. For natural gas (CCs and CTs), a net increase of only 3,822 MW (1,672 MW for NG-CCs and 2,149 MW for NG-CTs) is observed. ${ }^{48}$ New natural gas capacity is primarily driven by additional capacity or energy needs. ${ }^{49}$ In the REF scenario, lower than historical demand growth, increasing natural gas prices, new renewables capacity, and the assumed retirements yield little new natural gas capacity. An important context is that reserve margins in most regions in the Western Interconnection are well exceeded in many model years. In fact, in 2010, the interconnectionwide installed capacity was $48 \%$ greater than the peak system demand while planning reserve margins range from 13 to 15\% (NERC 2011). This comparison is imperfect as it does not account for regional reserve requirements and installed capacity, or non-coincident peak loads, and it does not de-rate nameplate capacities using the capacity credit. Nonetheless, it does illustrate an excess in overall system capacity.

As the planning reserve constraints become binding, as a result of load growth and plant retirements, the model's ability to estimate capacity credit becomes increasingly important.

\footnotetext{
${ }^{48}$ The analysis is restricted to new solar PV, wind, and natural gas capacity except for planned capacity of other technology types (see Section 2.4).

${ }^{49}$ Significant shifts in fuel or capital costs could also lead to economic competitiveness of new generating capacity over the existing fleet. We did not find this in the REF scenario.
} 
Under the REF scenario, RPS-driven deployment of renewables reduces capacity needs from the thermal fleet as new renewable capacity offers some capacity value. For the REF scenario, we estimate a bulk average combined wind and PV capacity credit, aggregated across all four reserve sharing groups, of 1,946 MW (19\% aggregate capacity credit as a percentage of installed solar and wind capacity) in 2010, growing to $16,744 \mathrm{MW}$ (22\% capacity credit) in 2030 . Increasing aggregate wind and solar capacity credit through time directly reflects the increasing solar-to-wind ratio over the model time period

On a marginal basis, which is more relevant for new investment decisions, RPM estimates the focus region average capacity credit to be roughly $7 \%$ for wind and $56 \%$ for PV in 2030 . We find that for the focus region, the capacity credit for both wind and solar remain relatively constant over time with only slight degradation for PV due to increasing, but modest, solar penetration levels found in the region. In contrast, across the Western Interconnection the marginal capacity credit for solar declines sharply from 2015 to 2030 due to the higher solar penetration found outside of the focus region. On the other hand, wind marginal capacity credit increases slightly after 2020 as a result of higher capacity factors and the geographic distribution of wind deployment. On net, we find that wind and solar have nearly the same marginal capacity credit by 2030 across the Western Interconnection. Figure 8 shows these trends in changing marginal capacity credit of newly installed solar (top) and wind (bottom) capacity.

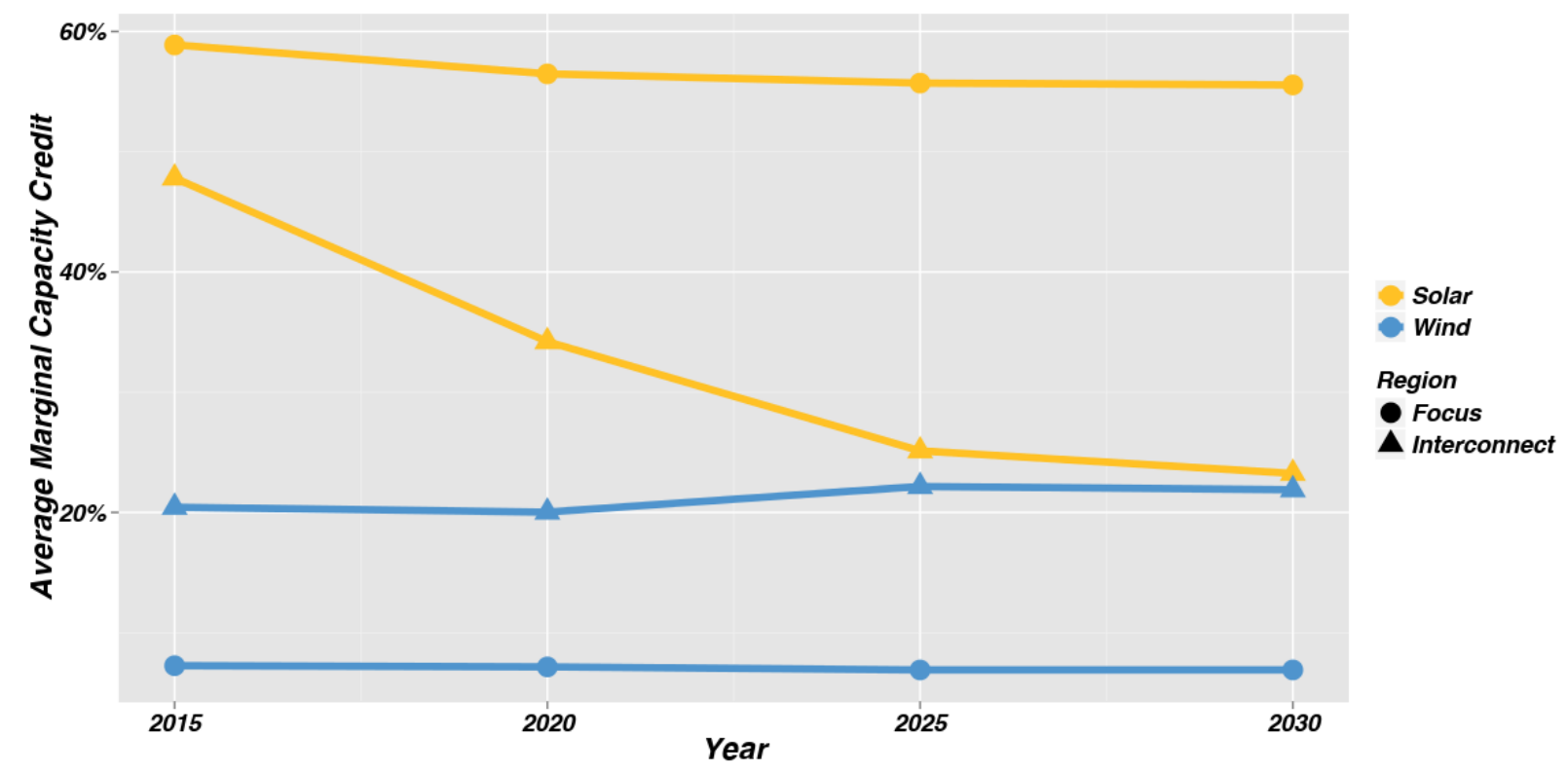

Figure 8. Average (over resource-weighted resource regions) marginal capacity credit for wind and solar technologies, for the CO-centric focus region and the Western Interconnection, as calculated in the REF scenario

Figures 9 and 10 show geographic results from the REF scenario. Figure 9 presents the 2030 cumulative installed wind and solar capacity in and around Colorado. The model decision on the location of new renewable capacity considers resource availability, resource quality, and the relative access to and availability of transmission. For example, solar capacity in Figure 9 is concentrated in three primary regions: (1) along the Front Range, where the residential and commercial loads of Colorado are greatest, (2) in the San Luis Valley in the south-central region 
of the state where the highest quality solar resources exist, and (3) in the southwest region where a combination of high solar resource quality and transmission is available. While some resource exclusions have been applied, RPM does not comprehensively evaluate all siting, permitting, and other land use factors. Figure 10 shows the transmission nodes where this new capacity is connected as well as the 2010 grid and generation capacity of the focus region. As will be discussed in Section 5, accounting for the local connection costs of new renewables projects can play an important role in CEMs.

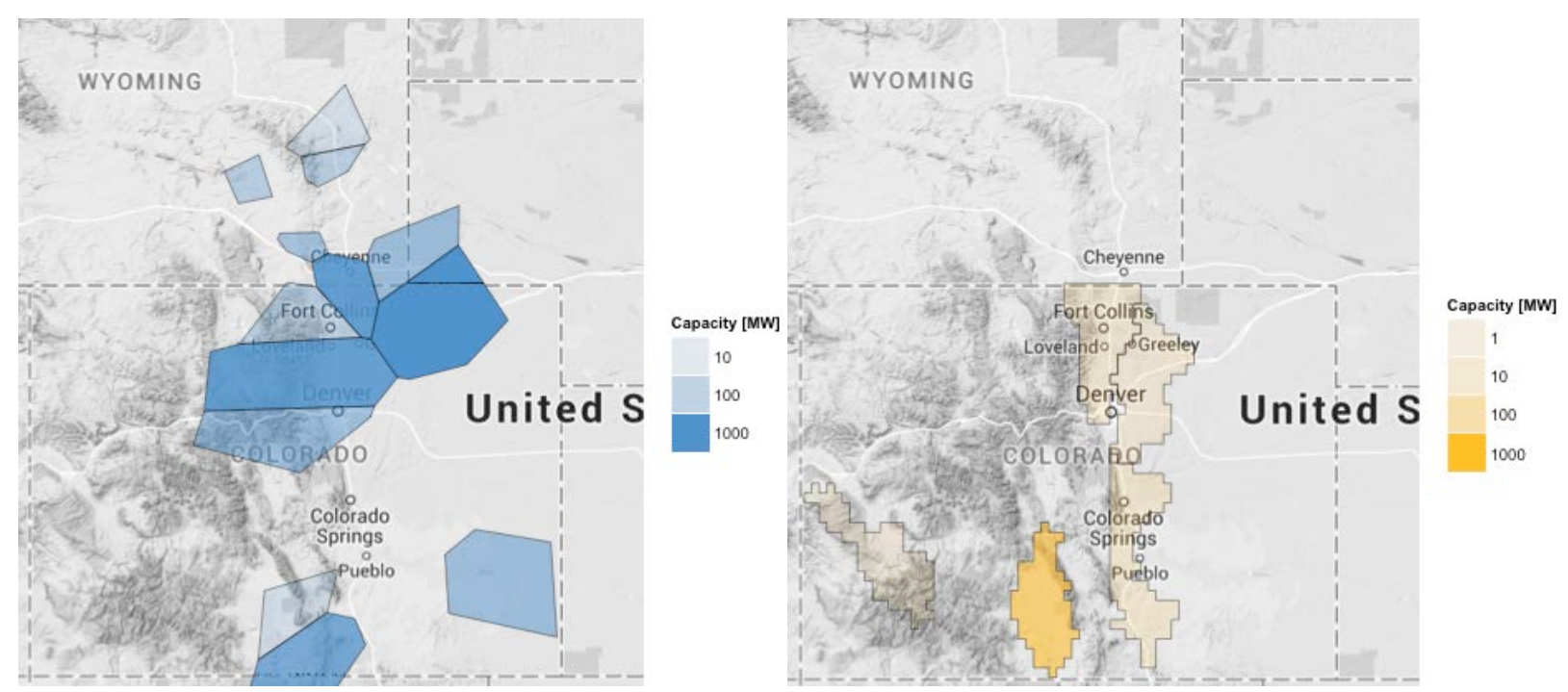

Figure 9. Installed wind (left) and solar (right) capacity in Colorado and surrounding regions under the REF scenario in $\mathbf{2 0 3 0}$
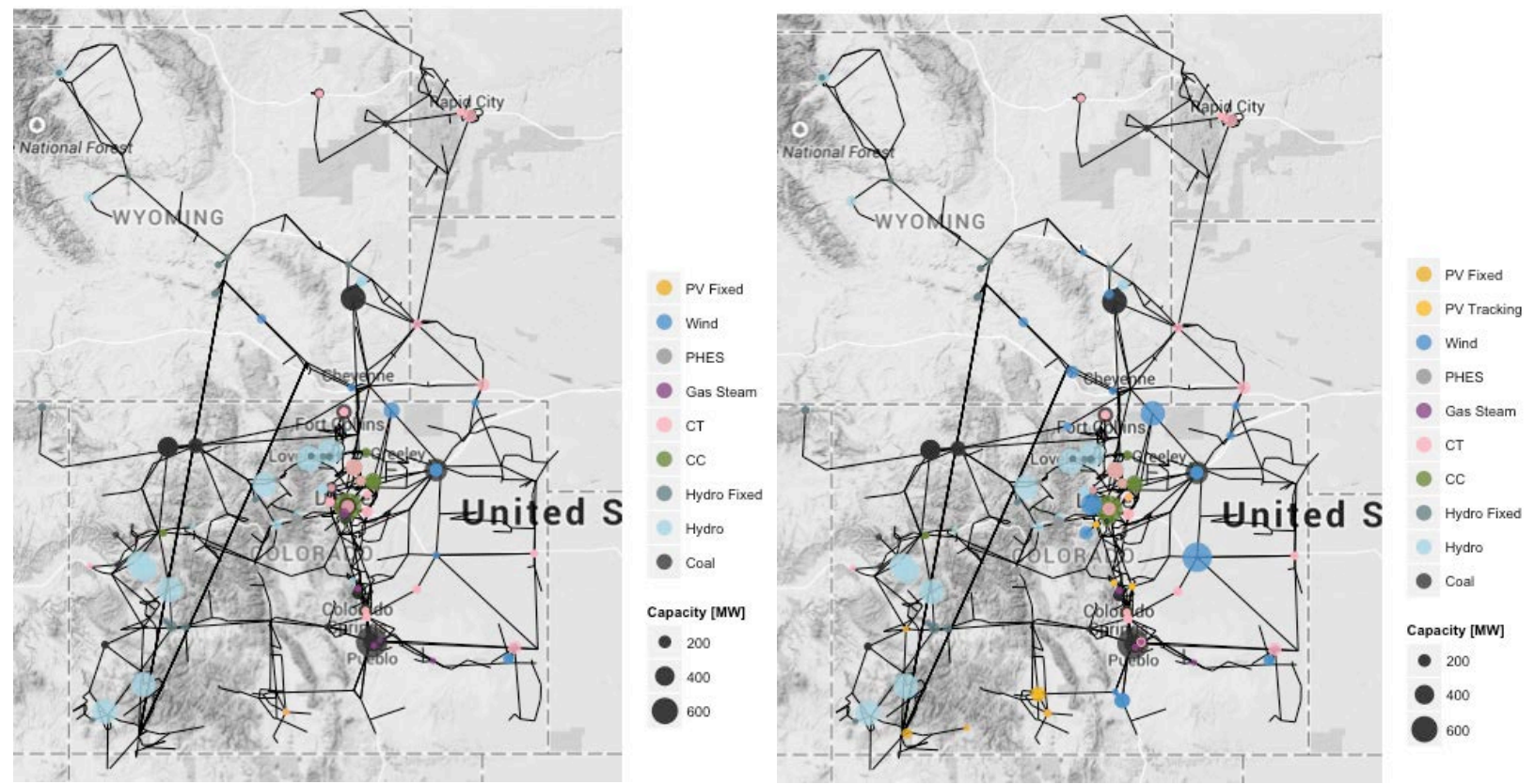

Figure 10. Installed capacity in 2010 (left) and estimated total capacity (including additions) in 2030 (right) for all nodes within the focus region 


\subsection{Generator Dispatch}

Figure 11 shows dispatch results for the Western Interconnection under the REF scenario. The results qualitatively demonstrate how system dispatch characteristics change with increasing demand and with increasing renewable penetration. For example, when moving toward increasingly high demand dispatch periods (for a given year), greater reliance on natural gas generation is found and other thermal units produce electricity near their maximum availability limits. Figure 11 also shows how the net load curves change as renewable deployment increases; the effects of increased solar PV penetration are most prominently seen through diurnal cycles and dips in net load during the middle of the day. The impact of wind is more subtle in this figure, as the largest differences are observed between dispatch periods. This is in contrast to the strong diurnal cycle for solar. Wind generation follows significant seasonal patterns, with greater wind generation during the Low dispatch period, which includes many spring and autumn days, and lesser wind generation during the High summer dispatch periods. While these high-level trends are observable in the dispatch stacks from Figure 11, it is noted that these dispatch results are smoother than expected due to the large interconnection-wide system presented and the fact that the hours are non-chronological and averaged within each dispatch period (see Section $2.2)^{50}$

\footnotetext{
${ }^{50}$ The lack of unit commitment representation in the REF scenario also leads to greater variation in traditional "baseload" generators like nuclear and coal compared with historical practice. Section 5.2 shows how adding "must run" constraints would change this behavior.
} 


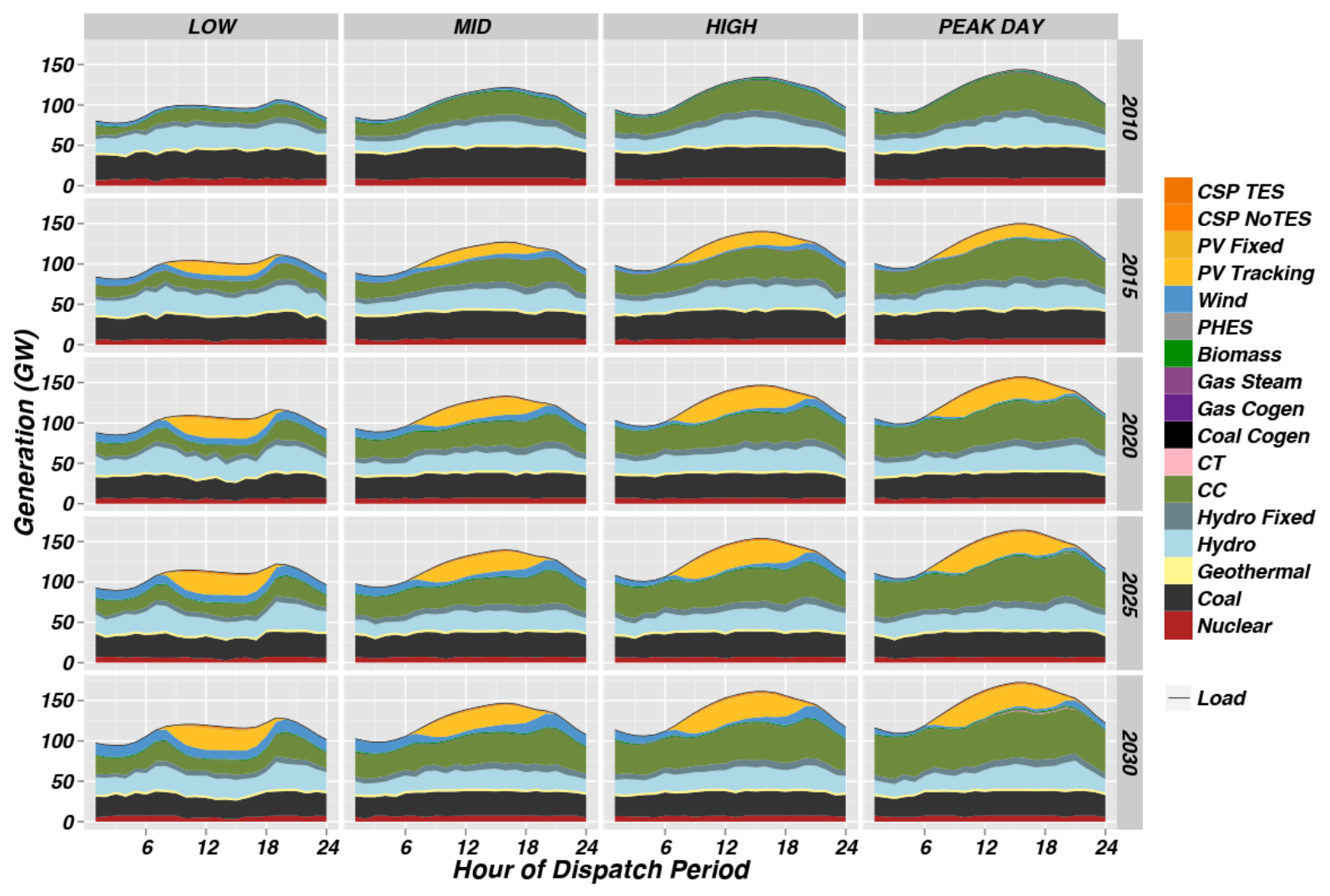

Figure 11. Western Interconnection dispatch stacks by dispatch period and year under the REF scenario

Dispatch results for the CO-centric focus region are presented in Figure 12. While many trends in Figure 12 are similar to those of Figure 11, the smaller system with only two BAs demonstrates more discrete dispatch decisions than the Western Interconnection-wide results in Figure 11. As with the interconnection-wide results, Figure 12 shows increased reliance on more-expensive natural gas generation when moving from lower demand periods (e.g., spring) to higher ones (e.g., summer) for the focus region. In fact, during the Low dispatch period, coal can be on or near the margin for multiple hours, whereas this rarely occurs during the higher-demand periods. Greater reliance on natural gas is found over time; however this is somewhat mitigated by new RPS-driven renewable deployment, especially deployment of wind. Figure 12 also reveals how "Imports" and exports (negative "Imports") change within a year and as the system evolves. We find that during Low and Mid dispatch periods, the focus region is a net exporter of electricity; however, during the High and Peak periods, the region relies on imports to meet the mid-day hours of highest electricity demand. ${ }^{51}$ This pattern becomes increasingly apparent over time with assumed load growth in the system. On net, annual imports do not demonstrate a strong trend (see Figure 7); however, the results from Figure 12 reveal that the focus region is increasingly relying on neighboring regions for balancing as the model views this as a lower cost option compared with installing more local capacity.

\footnotetext{
${ }^{51}$ Hourly imports are plotted as "Transmission" while stacked generation above the load line represents hourly exports for the focus region.
} 


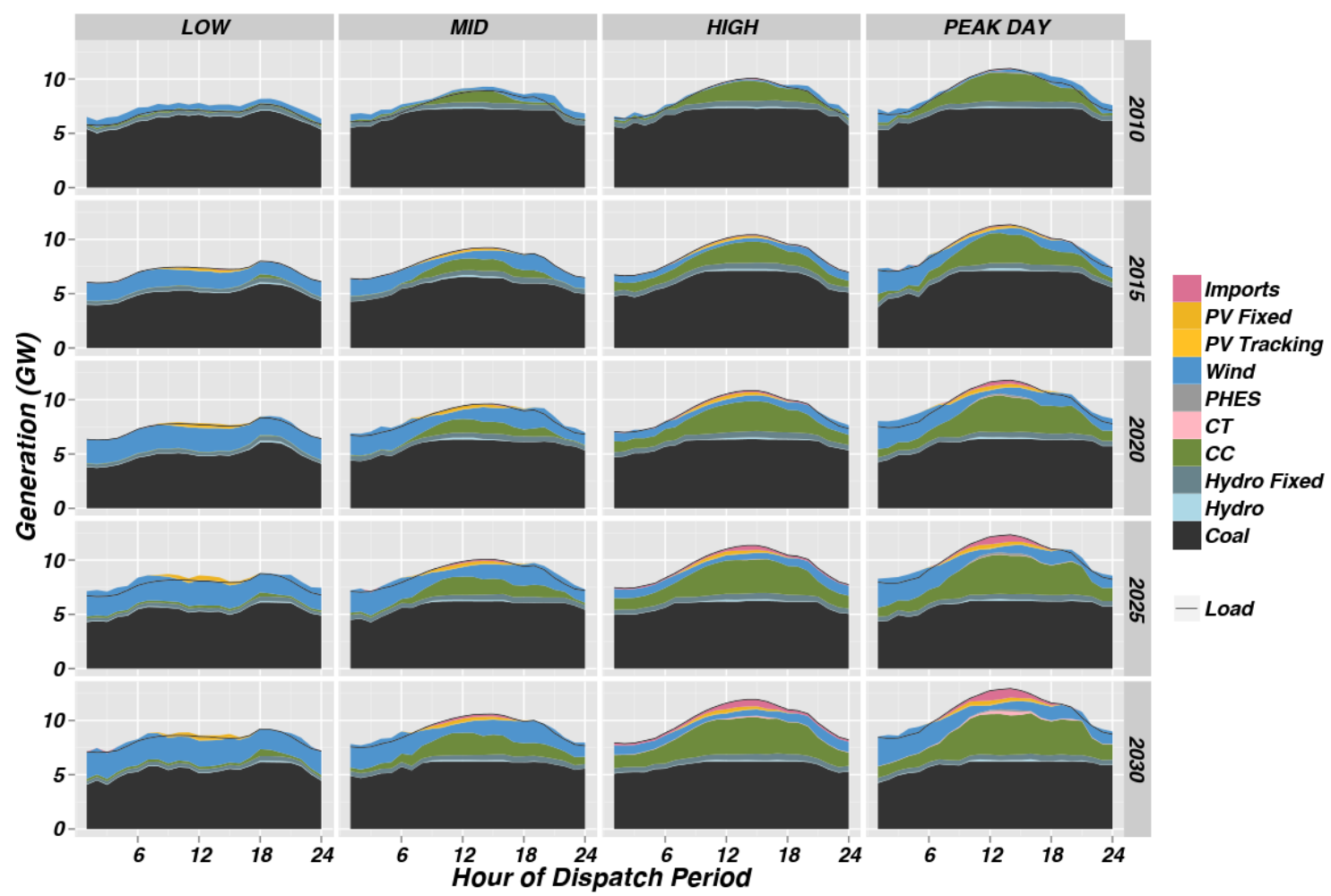

Figure 12. CO-centric focus region dispatch stacks by dispatch period and year under the REF scenario

In the REF scenario, operating reserves are co-optimized with the dispatch and investment decisions. Figure 13 shows the annual reserve provision results of the $\mathrm{CO}$-centric focus region under this scenario. Increases in regulation and flexibility reserves over time are direct results of increasing electricity demand and renewable deployment. Spinning reserve requirements are flat, as we assume them to be based on the single largest contingency in the region. The model finds reserves to be provided by all eligible technology categories, including coal-fired, hydropower, and natural gas-fired technologies, but with somewhat increasing reliance on natural gas-fired units in the long term. While the provision of operating reserves by unit can be degenerate or near-degenerate in many models, whether or not reserves are modeled can significantly influence model results, as demonstrated in Section 5. 


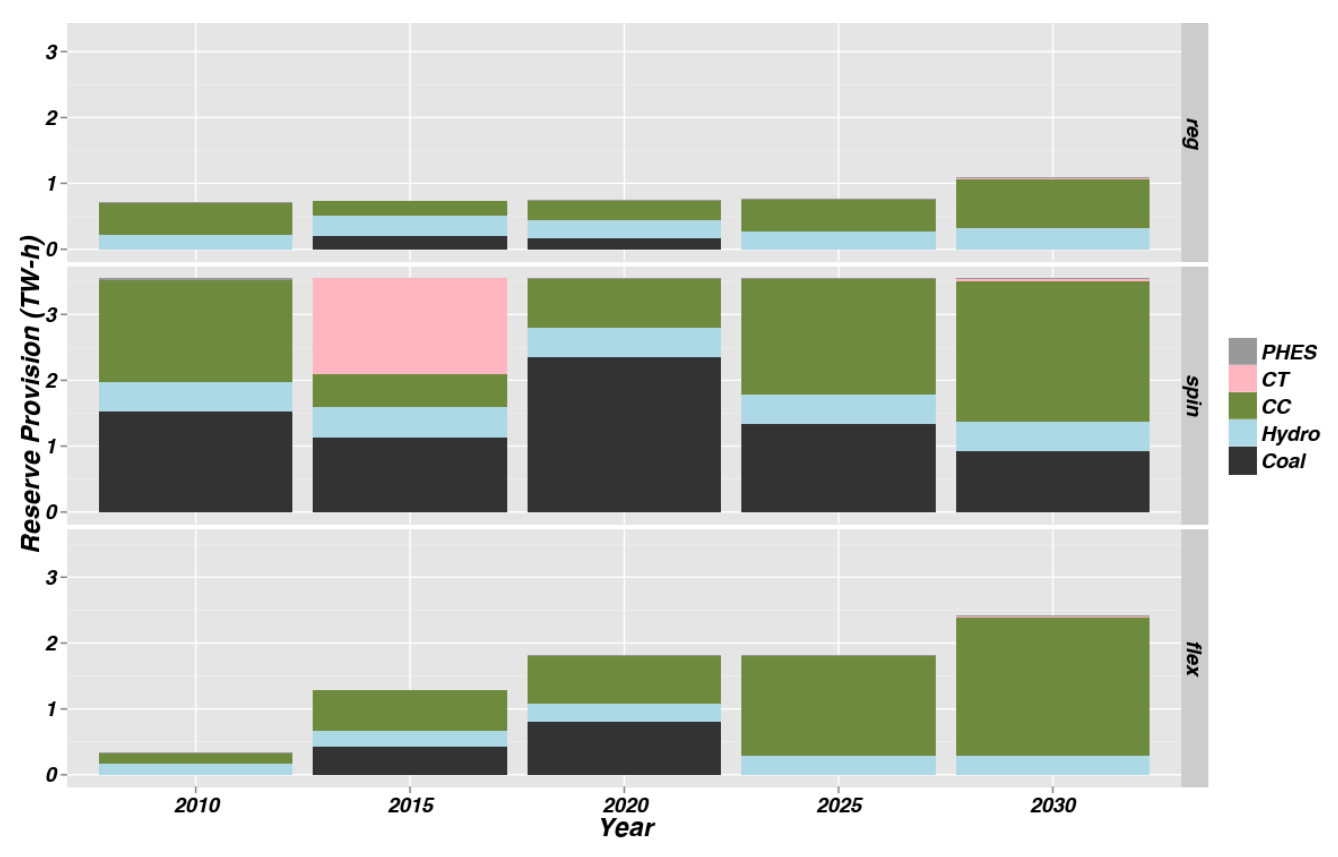

Figure 13. Annual reserve provision in the CO-centric focus region for regulation (reg), spinning (spin), and flexibility (flex) reserve products in the REF scenario

\subsection{System Costs}

We evaluate total electric system costs, including costs associated with new capital expenditures, O\&M costs for new and existing infrastructure, fuel expenditures from new and existing generators, and transmission-related expenditures for each scenario. Total system costs are evaluated on a net present value (NPV) basis from 2015 to 2030 using a 3\% (real) discount rate. This cost metric excludes any fixed costs, including capital or fixed O\&M costs, for the existing (2010) infrastructure as those data are unavailable. Because all new (2015-) capital expenditures are assumed amortized over 20 years in RPM, the system cost metric makes the same assumption and the present value of these equal annual payments are calculated accordingly. Fixed costs associated with any prescribed capacity that occurs between the 2010 and 2015 solve years (i.e., between 2011 and 2015) are included and assumed to begin in 2015. Variable O\&M and fuel costs are interpolated between solve years. Plant decommissioning costs and transmission maintenance costs are excluded from our analysis. ${ }^{52}$

Figure 14 shows the Western Interconnection NPV system costs for the REF scenario. The NPV system costs are broken down by variable generation (VG), including solar PV and wind, and non-VG technologies. Western Interconnection system costs total $\$ 335$ billion, of which the majority (54\%) is associated with fuel costs. Generator capital costs, dominated by investments in new renewable capacity, are the second largest category (36\%) followed by O\&M costs $(10 \%)$. Transmission-related costs in the REF scenario are entirely associated with spur line

\footnotetext{
${ }^{52}$ As described in Section 2, we include hurdle rates for inter-BA power transfers in RPM; however, as these rates are only included as a modeling technique to reflect friction for power transfers and are not necessarily real costs, they are not included in our NPV system cost metric. If included, they comprise only a small fraction $(<2 \%)$ of total system costs in the REF scenario.
} 
expenditures for new wind and solar PV capacity as new inter-BA or inter-nodal transmission capacity is not chosen under the REF scenario. These costs total only $2 \%$ of total system costs and $8 \%$ of total VG capital expenditures.

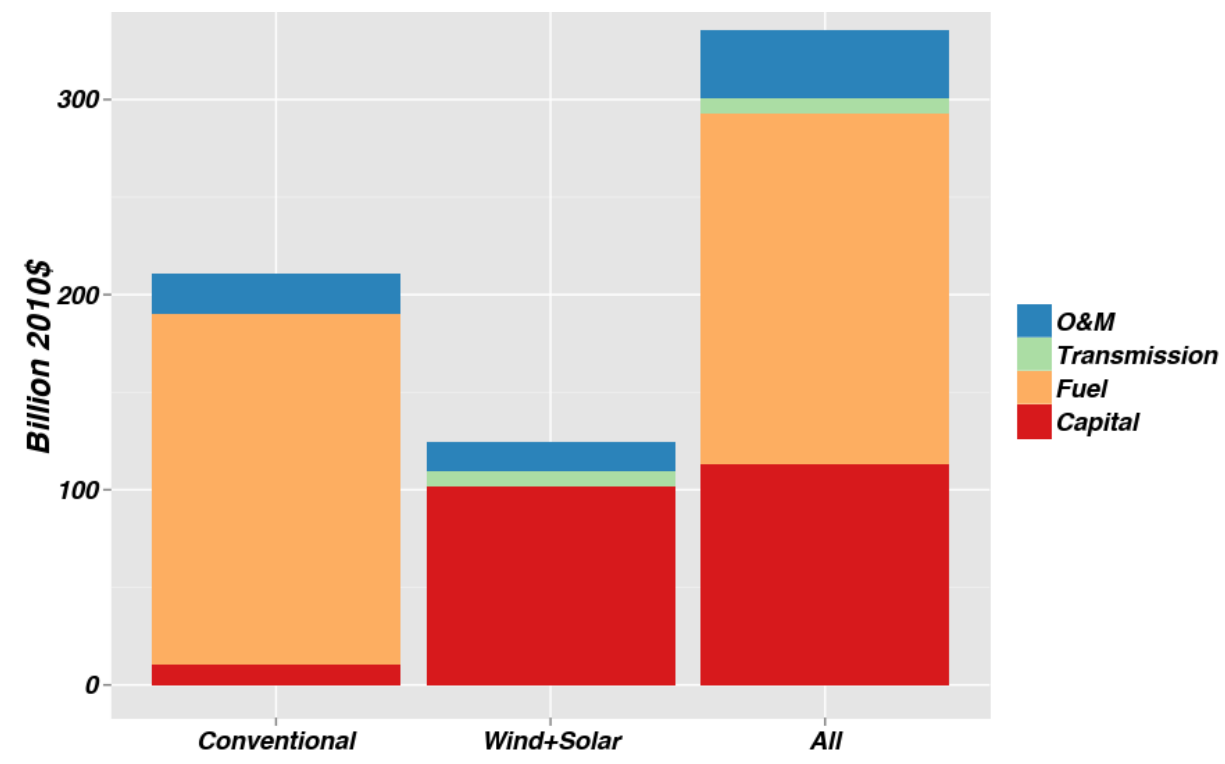

Figure 14. Net present value of system costs for $2015-2030$, with a $3 \%$ real discount rate, for the Western Interconnection under the REF scenario

\subsection{Emissions}

Electric-system carbon dioxide $\left(\mathrm{CO}_{2}\right)$ emissions are another key output of RPM. These estimates include only direct combustion-related emissions and exclude other life cycle emissions, such as for fuel extraction or emissions associated with equipment manufacturing. They also do not include non- $\mathrm{CO}_{2}$ greenhouse gases.

Figure 15 (left) shows the annual system-wide $\mathrm{CO}_{2}$ emissions for the REF scenario. $\mathrm{CO}_{2}$ emissions in 2010 are estimated to be 337 million metric tons, and they decline by $14 \%$ to 289 million metric tons in 2020. These reductions are a result of increasing renewable deployment and greater reliance on natural gas relative to coal (see Figure 6). Fossil fuel switching over this period is a result of low natural gas fuel prices (less than \$5/MMBtu for 2015-2020) and coal plant retirements. After 2020, $\mathrm{CO}_{2}$ emissions increase and reach 308 million metric tons in 2030. This slight growth in emissions is a consequence of increasing natural gas-fired generation with little change in coal-fired generation to meet growing electricity demand. Despite the increase in absolute $\mathrm{CO}_{2}$ emissions from 2020-2030, the carbon intensity plot (Figure 15, right) demonstrates that increases in total system demand result in reductions in the relative $\mathrm{CO}_{2}$ emissions per MWh of generation. In addition, as we include existing policies only, RPS-driven demand for new renewables capacity is more limited in this latter period than it is in the pre2020 period. Based on simple linear interpolations between years, cumulative (2015-2030) $\mathrm{CO}_{2}$ emissions total 4,483 million metric tons in the REF scenario. 

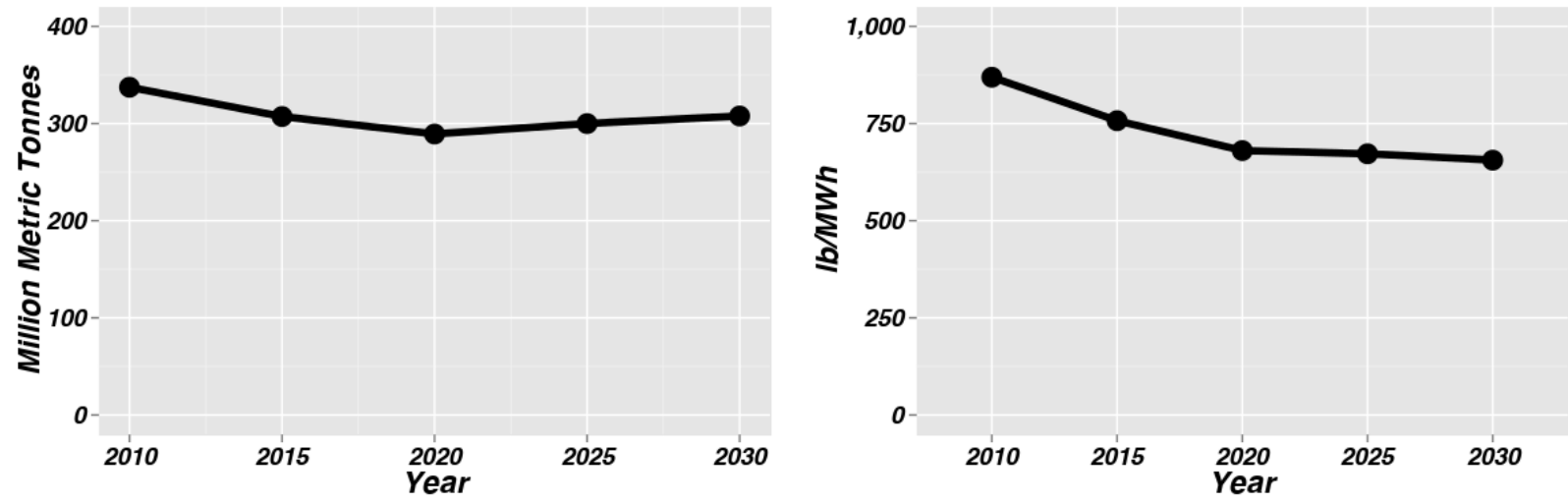

Figure 15. $\mathrm{CO}_{2}$ emissions (left) and $\mathrm{CO}_{2}$ intensity (right) for the Western Interconnection under the REF scenario

Carbon prices or carbon constraints have not been applied to any of the modeled scenarios in the present report. However, a price on $\mathrm{CO}_{2}$ emissions or a cap can be applied in the model. 


\section{Sensitivity Scenario Results}

In this section, we compare results from the 10 sensitivity scenarios (see Section 3 ) with the REF scenario results presented in Section 4. We highlight key differences - particularly for capacity expansion decisions, annual generation and hourly dispatch results, system costs, and emissions - and we describe the implications of those differences for model development and design. An important consideration is the computational tractability for the different model configurations. While greater detail and resolution would (presumably) increase model accuracy, computational time can create practical constraints on model configurations.

The computation times for each of the simulations from the model configuration scenarios are shown in Figure 16. The 2010 computation times (red) represent simulations without capacity expansion variables (i.e., operations only-no investment decisions). With the exception of the DCOPF simulation, which requires 175 minutes to compute, the 2010 computation times are relatively insensitive to configuration changes and solve in at most a few minutes. The simulation years that include capacity expansion variables (2015-2030) are also highly influenced by the DCOPF configuration. More generally, across all configurations, we find that the investment decisions in RPM increase the computation time for each solve by about two orders of magnitude. There are few clear trends across the different model configurations, with largely unpredictable computation times across years and scenarios. However, Figure 16 demonstrates that having increased detail on power flows (e.g., DCOPF) and increased dispatch periods (e.g., 4DAY) decisively increases computation times. In the other direction, ignoring operating reserves (e.g., NOR) can lead to shorter computation times; however, the magnitude of impacts is less in this case. For reference, total computation time for all model years total 793 minutes (13.2 hours) in the REF scenario.

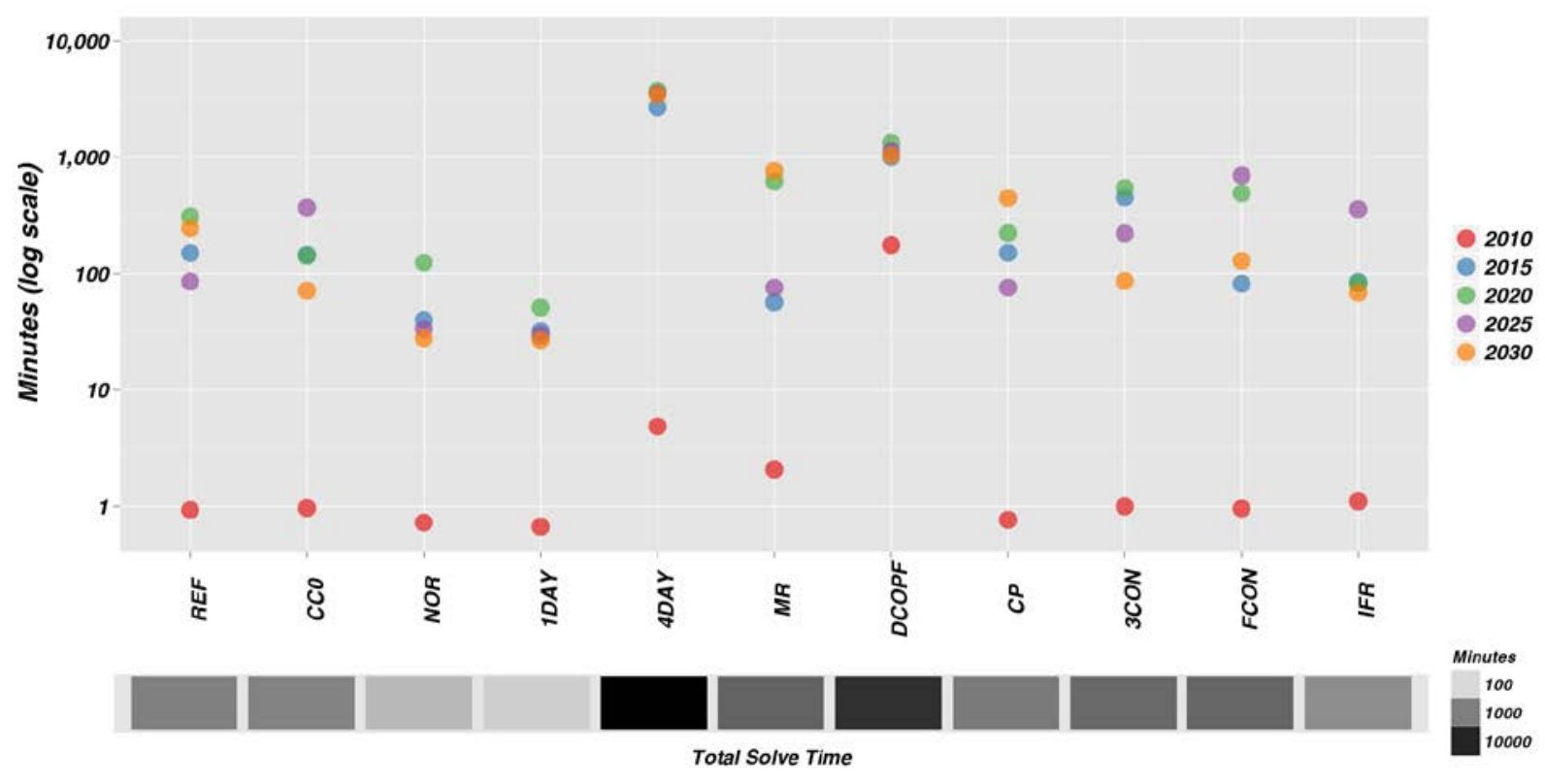

Figure 16. Computation time for each model configuration scenario

Note: The scale is logarithmic. Colors (top) show the simulation time for each year. Shading (bottom) denotes the total simulation time for all years. 
While computation times presented are specific to the RPM and different modeling systems can result in dramatically different run times, these results illustrate how certain features can affect model complexity. These results are most relevant to optimization models. As a general principle, and subject to data availability, configurations with greater detail and resolution are preferred when possible or practical; however, our analysis highlights those features that can be simplified without a significant sacrifice of accuracy - at least for the system type and renewable penetration regime evaluated. The remainder of Section 5 explores the differences between each configuration scenario's results and highlights the tradeoffs between result quality and computation time.

\subsection{Installed Capacity}

When comparing all 10 sensitivity scenarios against the REF scenario, Figure 17 (left) shows that aggregate interconnection-wide capacity expansions are relatively insensitive to many model configurations. Figure 17 (right) shows analogous results for $\mathrm{CO}$-centric focus region capacity expansion. Capacity differences between sensitivity scenarios represent only a small fraction of total installed capacity (see Figures 6 and 7); however, some of the differences presented in Figure 17 can be sizeable for new incremental capacity decisions, such as those considered in utility planning.
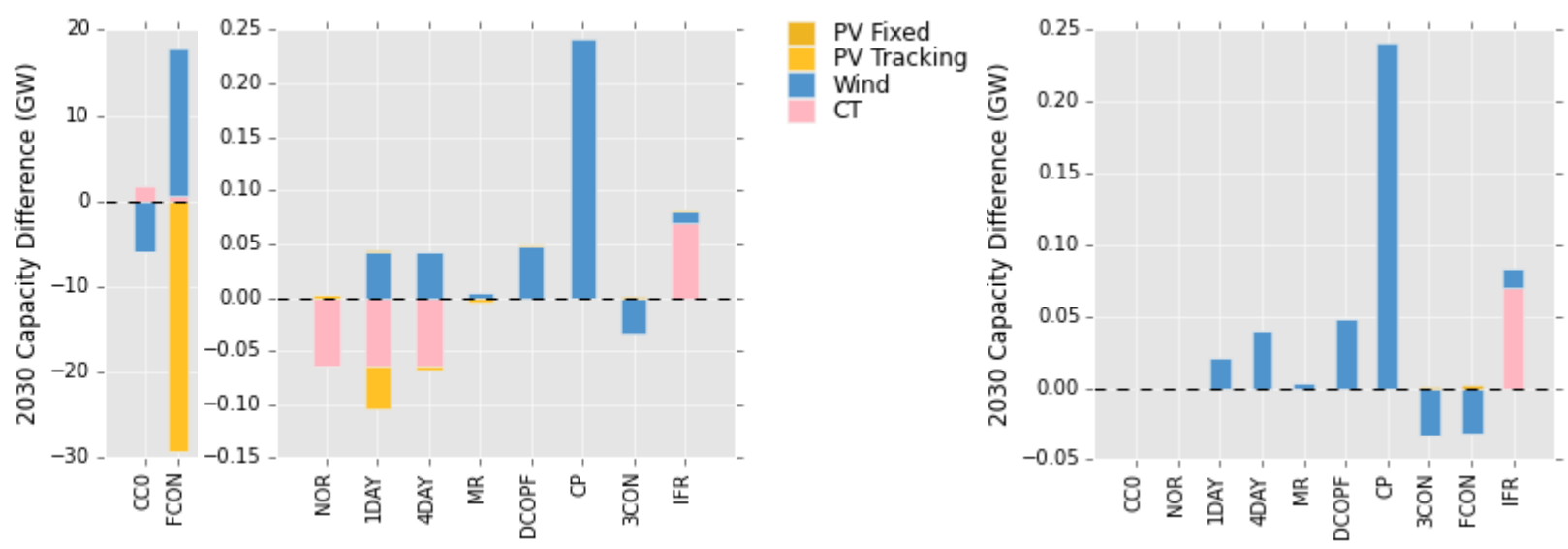

Figure 17. Differences in 2030 installed capacity (relative to the REF scenario) across the entire Western Interconnection (left) and the focus region (right) for all 10 sensitivities

The largest system capacity expansion differences occur in the Free Connection (FCON) scenario that relaxes the spur transmission line cost associated with building new wind and/or solar generation. In this scenario, the model favors capacity expansions in the form of wind over PV; however, this preference appears to be restricted to the non-focus region BAs. We conclude this is likely driven by the low resolution of the wind and solar resource regions in areas outside of the CO-centric focus region (see Figure 2). In addition to increased wind and decreased PV capacity, the FCON scenario results in a significantly different distribution of resources. Figure 18 shows the Western Interconnection-wide wind and PV (tracking) capacity in 2030 for the REF and FCON scenarios. Not only is more wind built in the FCON configuration than in the REF configuration, the resulting wind capacity is more geographically distributed. 

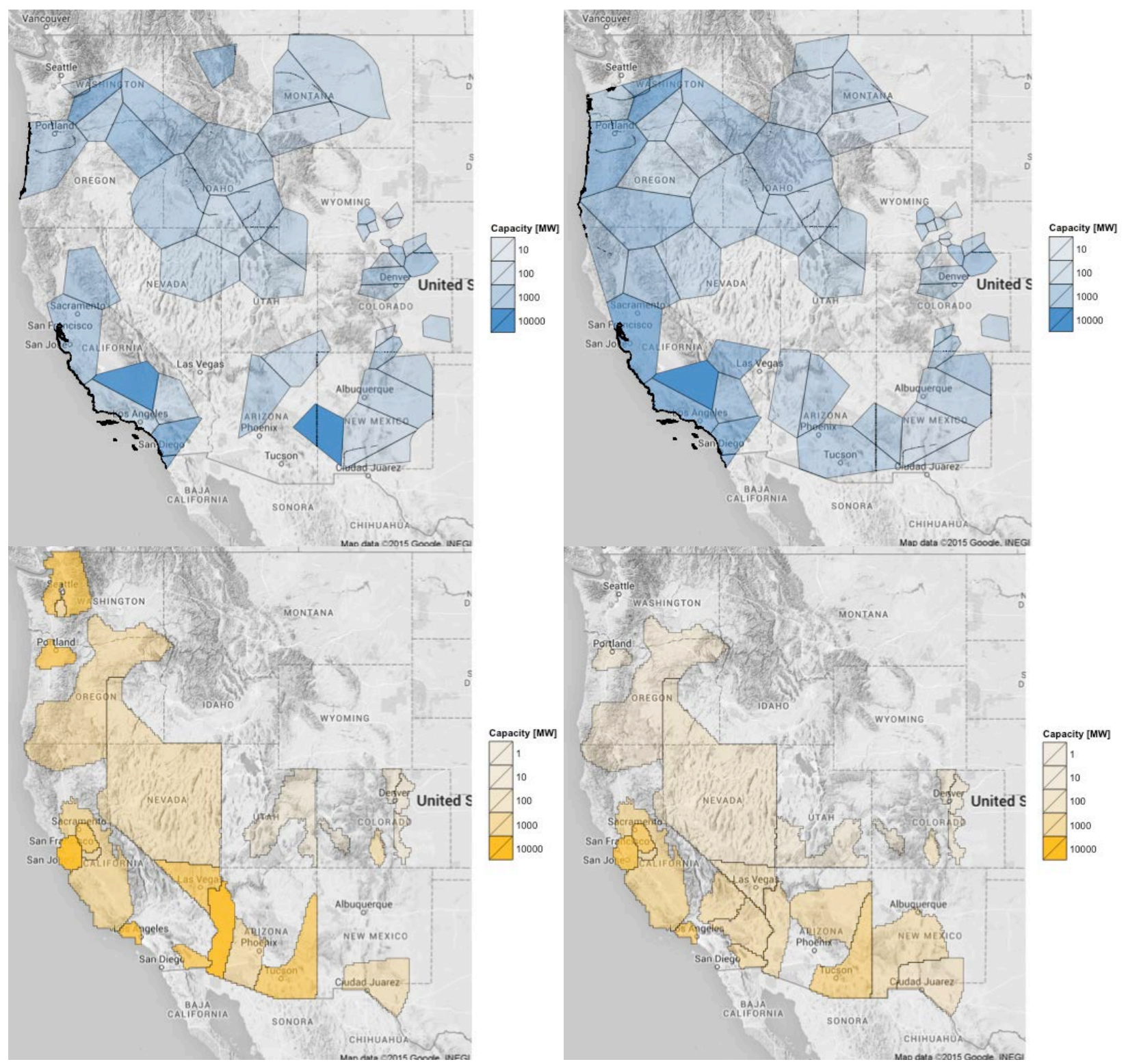

Figure 18. Capacity and location of wind (top) and PV Tracking (bottom) in 2030 for the REF scenario (left) and the FCON scenario (right)

This result implies that the treatment of spur lines for new renewable projects can be an important driver for the type and location of new renewable capacity chosen by CEMs. Because RPS targets are primary drivers of new renewable deployment in the scenarios modeled, our analysis does not directly evaluate the extent to which spur lines drive the economic competitiveness of renewables versus non-renewables options under different contexts, but our results do imply that further research is needed to account for these effects within models. These results also highlight that if computational resources are adequate, higher spatial resolution modeling can help alleviate some of these issues.

Assumptions of renewable capacity credit also result in significant capacity expansion differences. Figure 17 shows that when no capacity credit is given to wind and solar PV (i.e., 
CC0 scenario), an additional 1,800 MW of NG-CT capacity is required and nearly 6,000 MW of wind is not chosen by the model across the Western Interconnection. ${ }^{53}$ The CC0 scenario is representative of utility planning processes that optimize new thermal generation investment first to meet reliability needs before adding renewable capacity for policy mandates. Our simulations indicate that this can result in more NG-CT capacity (and associated costs) than one would otherwise require to meet planning reserve margins. In addition, the lower renewable capacity in the $\mathrm{CC} 0$ scenario points to the lower economic valuation of renewable technologies-and thereby their deployment selection - when their capacity credit is omitted.

The transmission representation sensitivities (DCOPF and $\mathrm{CP}$ ) also result in relatively sizeable capacity expansion differences relative to the REF scenario, particularly for the focus region. Figure 19 (left) demonstrates the differences in each solve year between the DCOPF and REF scenarios. The DCOPF configuration generally restricts the model's ability to transfer power between nodes. Compared with the DCOPF scenario, the REF scenario consistently underestimates capacity expansion, especially wind capacity, by up to $50 \mathrm{MW}$, throughout each solve year; however, annual wind generation results (see Section 5.2) are nearly identical for these two scenarios. These results highlight that increasingly constrained transmission representations (i.e. DCOPF) limit access to higher quality wind resources and thereby require additional capacity to meet RPS requirements. However, the differences for the scenarios modeled are relatively small.
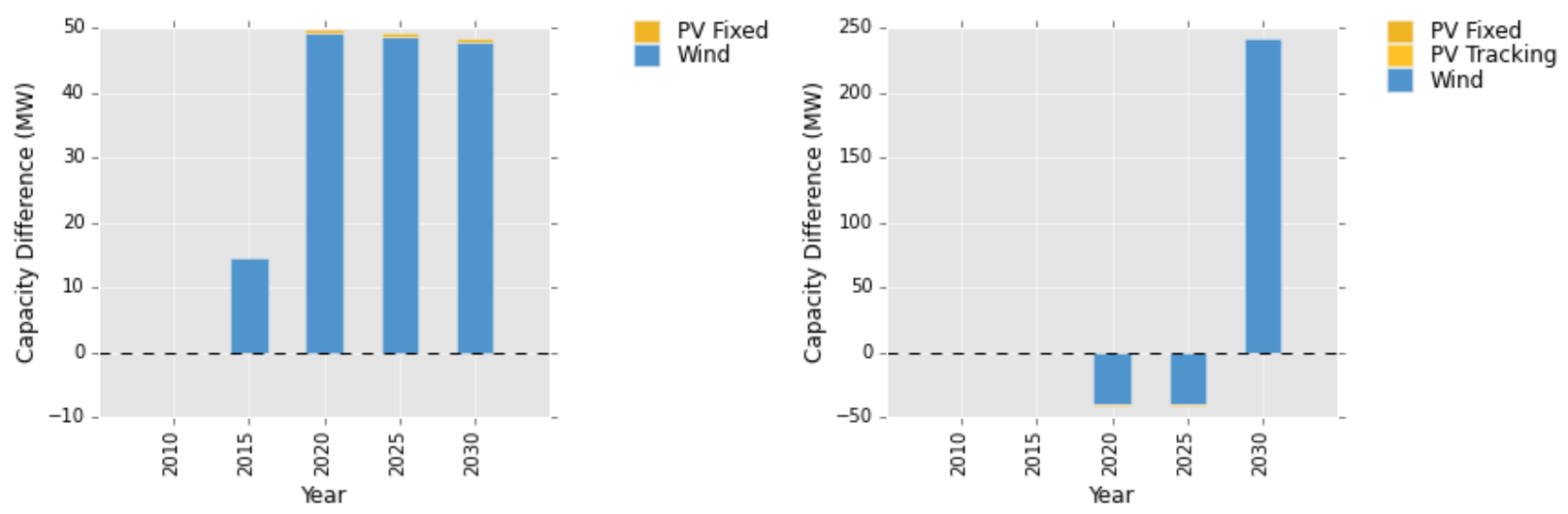

Figure 19. Differences in CO-centric focus region capacity (relative to the REF scenario) for each solve year (2010-2030) for the DCOPF (left) and CP (right) scenarios

When transmission constraints are relaxed (e.g., CP scenario), higher quality renewable sites become more economically accessible. For 2020 and 2025, the CP scenario results in less wind capacity compared to the REF scenario (see Figure 19, right) as a direct result of accessing higher capacity factor wind resources. ${ }^{54}$ By 2030 , the CP scenario ultimately yields greater wind capacity than the REF scenario. During this period and under the technology and fuel assumptions used, the elimination of transmission flow limits overestimates the available high quality wind resource that the model chooses in the focus region, by about $250 \mathrm{MW}$. This

\footnotetext{
${ }^{53}$ Essentially no difference is found within the focus region between the $\mathrm{CC} 0$ and REF scenarios as a result of the Rocky Mountain Power Pool showing up as overbuilt through 2030 under the stated demand growth assumptions.

${ }^{54}$ Annual wind generation in the CP and REF scenarios is nearly identical in 2020 and 2025 (see Section 5.2).
} 
additional wind capacity is in excess of the RPS requirements. These results highlight the importance of transmission limits when assessing future renewable options; however, the computational cost of advanced transmission modeling (e.g. DC OPF) is an important counterweight.

In the Islanded Focus Region (IFR) scenario, an additional 70 MW of NG-CT capacity is deployed within the focus region by 2030 compared with the REF scenario. As the name implies, the IFR model configuration effectively eliminates the ability of the focus region to import or export electricity to the rest of the Western Interconnection. The additional NG-CT capacity in this scenario is not installed to meet planning reserve requirements but is instead built to meet operating needs during high demand hours (see Section 5.2). During these hours, the REF scenario uses imports to serve electricity demands within the focus region, even though the focus region is a net exporter of electricity on an annual basis. The results from this scenario highlight the need to model interactions with neighboring systems in resource planning, as this interaction can often reveal lower cost alternatives to new capital investments.

\subsection{Generation and Dispatch Characteristics}

Annual generation differences between the sensitivity and REF scenarios, shown in Figure 20, stem from the combined effects of differences in installed capacity between scenarios (see Section 5.1) and the dispatch modeling representations of different configurations. For certain scenarios, such as $\mathrm{CC} 0$ and $\mathrm{FCON}$, variations in model configuration only affect investment decisions directly and any differences in dispatch result from changes in investments decisions. For example, under the FCON scenario, a trade-off of more wind capacity at the expense of solar PV capacity is found and the annual generation numbers reflect these changes. Similarly, decreased system-wide wind capacity under the $\mathrm{CC} 0$ scenario, compared to the REF scenario, results in less wind generation and a concomitant increase in generation from natural gas-fired plants. 

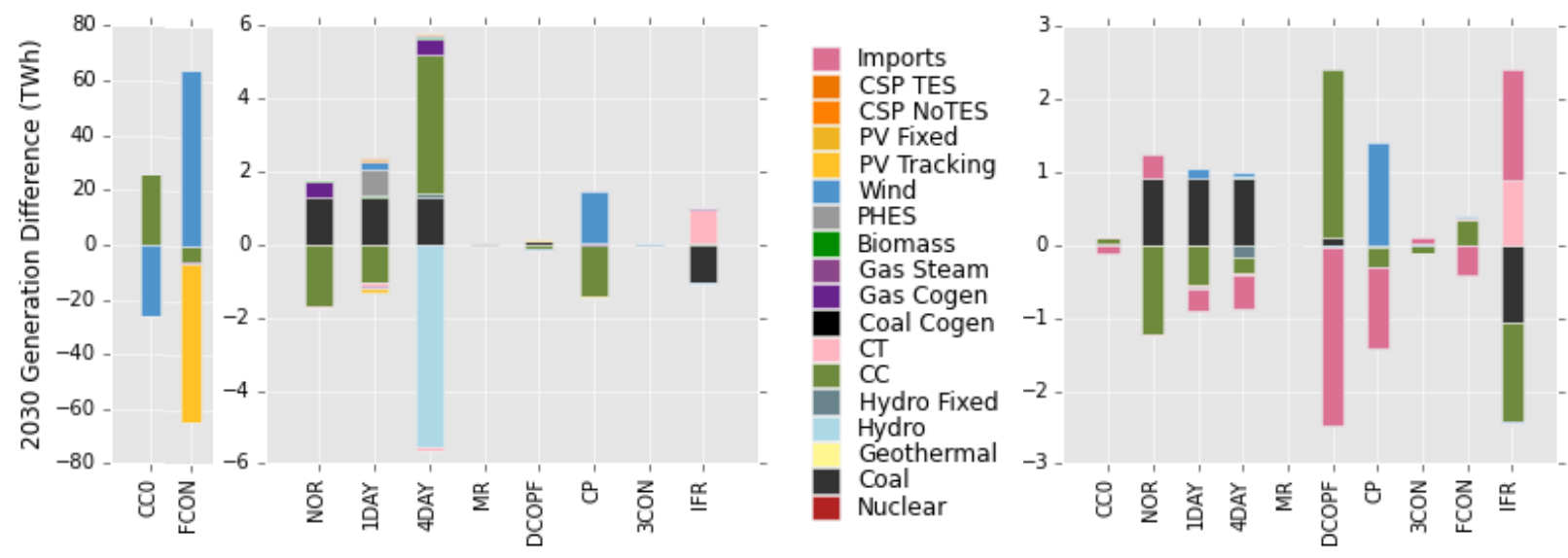

Figure 20. Differences in 2030 annual generation (relative to the REF scenario) across the entire Western Interconnection (left) and the CO-centric focus region (right) for all 10 sensitivities ${ }^{55}$

Some model configurations, such as those used for the MR scenario, are focused directly on dispatch modeling and had little impact on either investment or annual generation. Surprisingly, these scenarios also did not exhibit noticeable trends in hourly dispatch, except for smoother output from the aggregate coal and nuclear fleets. These null results indicate that simplifying complex dispatch model representations may not dramatically affect resource selection results as it does in other configurations. Care is needed in extrapolating these results to other scenario regimes. In particular, at higher renewable penetration levels curtailment may play a greater role in variable generation investment and better dispatch modeling may be needed to accurately compute expected curtailment levels and the associated economic impacts.

In the NOR scenario, in which operating reserve requirements are relaxed, we find no change in investment decisions, but modest changes in generation results were found. In particular, as a result of not having to provide operating reserves, lower-cost coal-fired generation increases at the expense of natural gas-fired generation. In other words, increased availability of coal-fired capacity to produce lower-cost electricity results in greater utilization of the coal units.

The selected configuration scenarios displayed in Figures 21-23 show the differences in system dispatch across the model configuration scenarios. Figures 21 and 22 show the focus region dispatch, for the Low and High dispatch periods respectively, of each generator technology on separate axes to facilitate comparison of dispatch differences between scenarios. When comparing the 1DAY (Figures 21 and 22) and 4DAY (Figure 23) configurations with the REF configuration, we find that dispatch of wind and solar is smoother in the REF scenario. This is due to the "average-day" configuration employed in the REF scenario. The 1DAY and 4DAY scenarios use a chronological dispatch configuration that models the first 24 and 96 hours (for 1DAY and 4 DAY, respectively) of each of the representative weeks for the non-peak dispatch periods. As a result, the profiles for wind, solar, and load have greater variability than when these profiles are averaged. However, sampling chronological dispatch periods also has its drawbacks

\footnotetext{
${ }^{55}$ For reference, in 2030 Western Interconnection annual system demand is 1,032 TWh, while 2030 RMPP annual demand is $75.1 \mathrm{TWh}$.
} 
in that results may be more sensitive to the sampling selection criteria. In addition, by sampling a relatively small set of hours without averaging the dispatch periods, the 1DAY configuration tends to misrepresent wind and solar dispatch, which can influence output profiles and valuation for capacity expansion decisions. Extending the dispatch period to the 4DAY configuration is intended to mitigate the effects of inaccurately representing wind and solar by modeling more hours and letting the model determine the optimal operation and capacity expansion endogenously. However, Figure 16 demonstrates that the additional duration of off-peak dispatch periods modeled in the 4DAY configuration make the computation time (225 hours) impractical for many model applications.

The IFR presents some of the most significant dispatch differences demonstrated by Figures 21 and 22. In general, the inability to import and export power in the IFR scenario requires additional generation from more flexible resources (e.g. PHES, NG-CT). Additionally, the IFR scenario shows a finite, non-zero imports and exports. This is due to the islanding method used to implement the IFR scenario. Islanding was achieved by imposing a $\$ 1000 / \mathrm{MWh}$ hurdle rate on power transfers across the focus/non-focus boundary. This method was chosen to ensure feasibility since there are some instances where non-focus load nodes are connected only to focus region nodes. With hard islanding constraints, these loads would remain unserved causing solution infeasibilities; however, the amount of imports and exports are largely negligible in the IFR configuration and the trends highlighted would likely remain even if hard islanding constraints can be applied. 


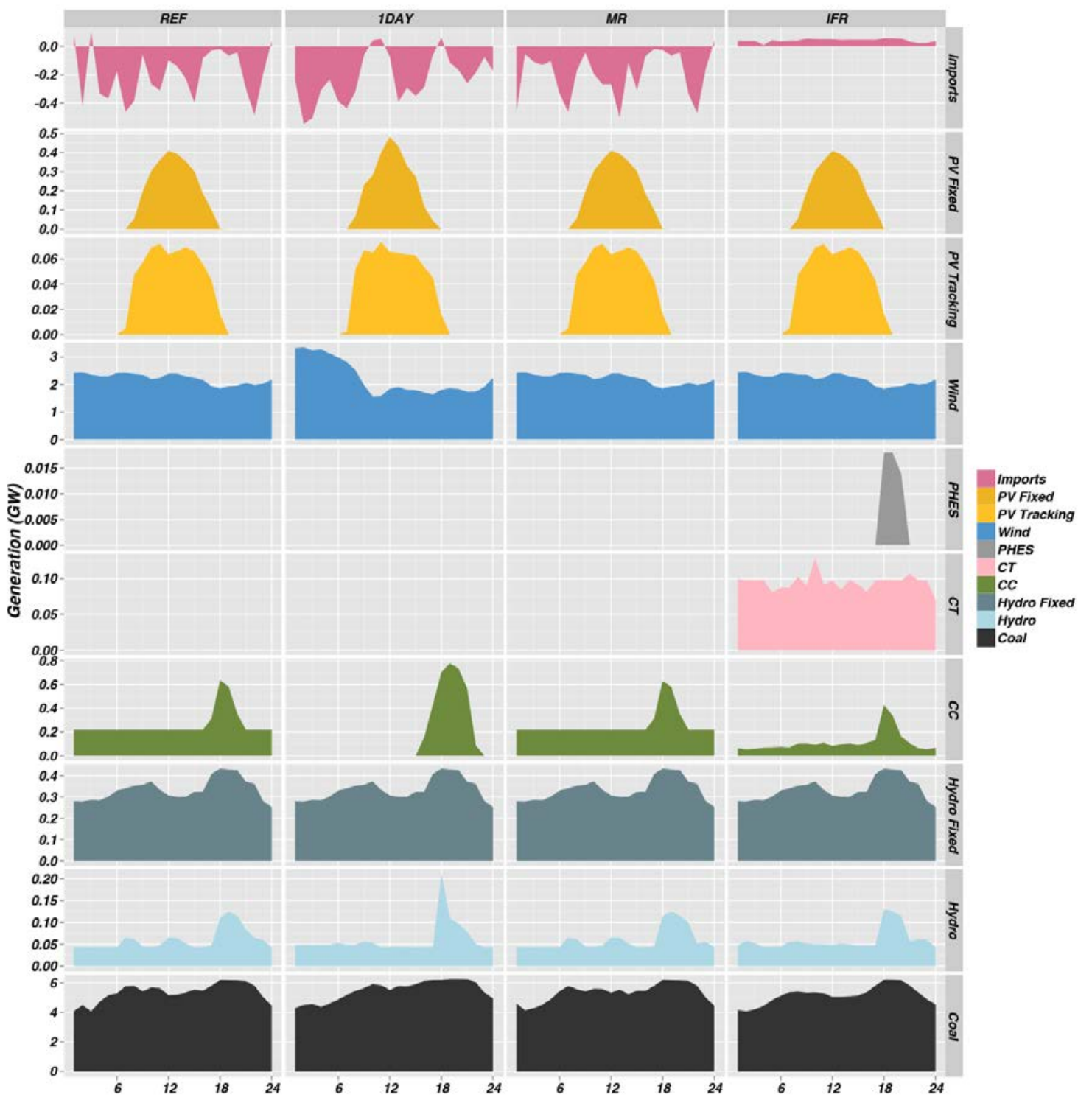

Figure 21. 'LOW' dispatch period CO-centric focus region 2030, by-technology for the REF, 1DAY, $M R$, and IFR scenarios 


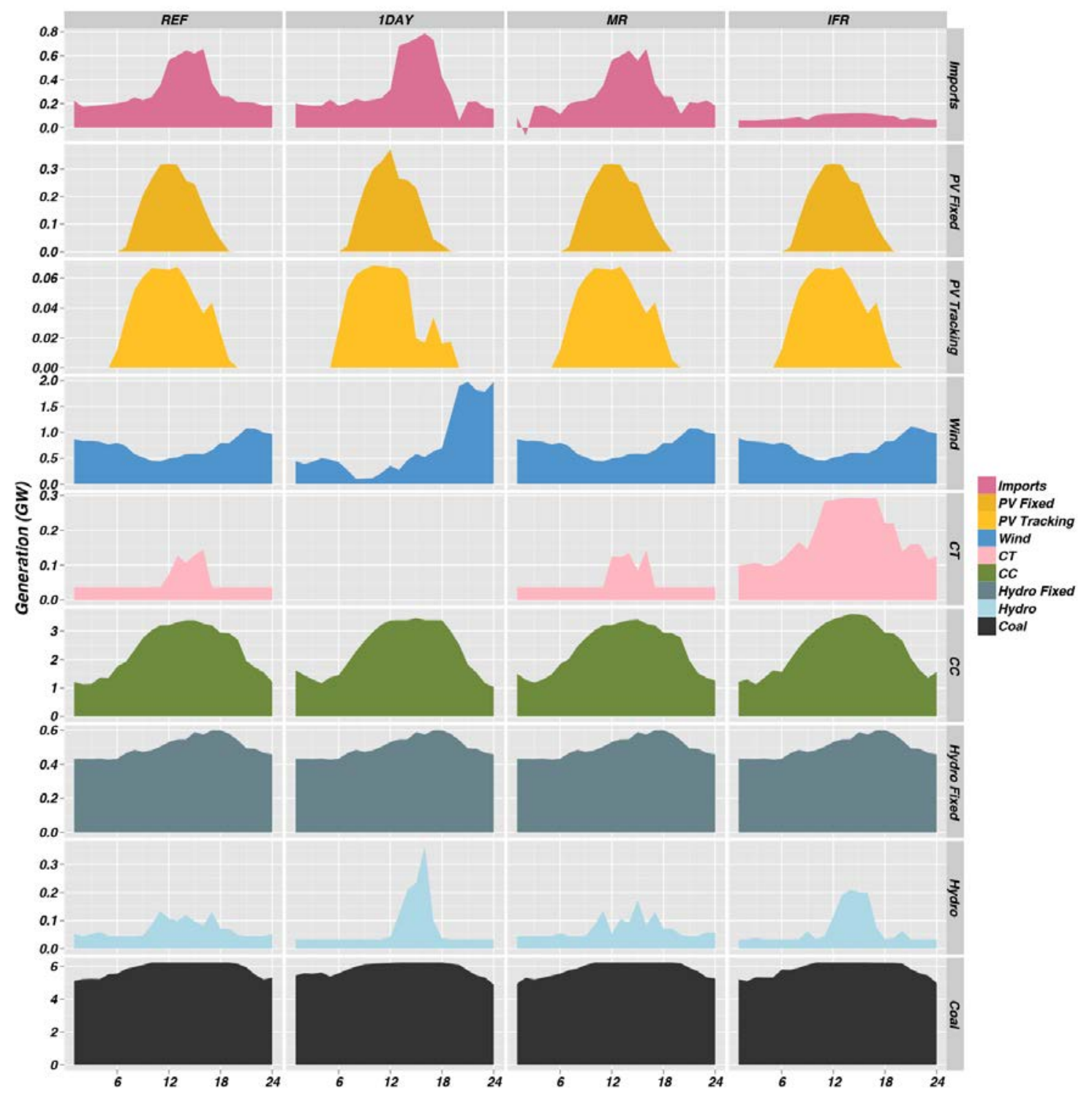

Figure 22. 'HIGH' dispatch period CO-centric focus region 2030, by-technology dispatch for the REF, 1DAY, MR, and IFR scenarios

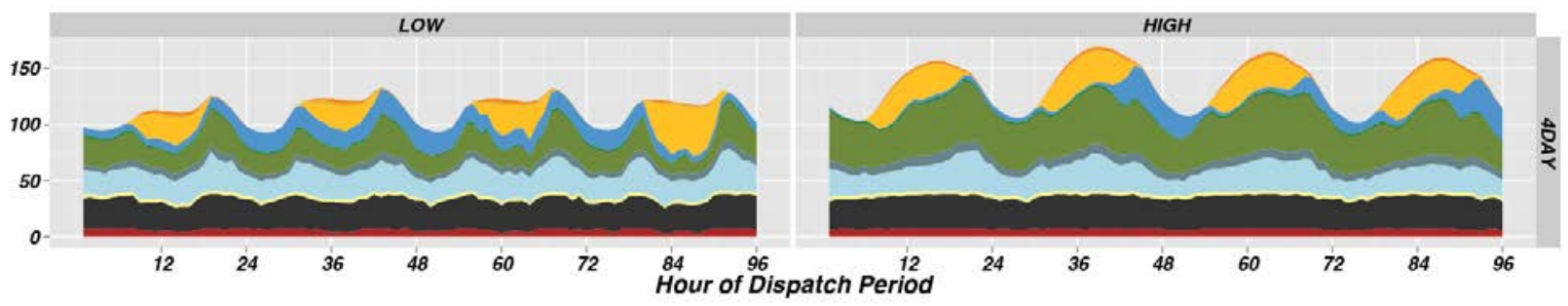

Figure 23. Dispatch stacks for system operation in $\mathbf{2 0 3 0}$ for each of the four dispatch periods (LOW and HIGH) for the 4DAY model configuration scenario 


\subsection{System Costs}

Differences in system cost across scenarios (Figure 24) are small relative to total system costs. Across most scenarios, system costs only change by up to $0.73 \%$ of the $\$ 335$ billion found for the REF scenario. These results are unsurprising given the magnitude of changes to annual generation and installed capacity across the scenarios. Also not surprisingly, when model restrictions or costs are relaxed (e.g., NOR, CP, FCON), total systems costs decline, albeit by a small amount. Conversely, more stringent or detailed model representations (e.g., 4DAY, MR, DCOPF, IFR) increase system costs by less than $\$ 3$ billion (see Figure 24).

Across all sensitivity scenarios, the $\mathrm{CC} 0$ and $\mathrm{FCON}$ scenarios result in the greatest changes to system costs. As described previously, undervaluing or ignoring the capacity credit of wind and solar (e.g., CC0) may lead to excess investments in system thermal capacity, and underinvestment in wind and solar projects. In addition, by improperly crediting renewable technologies for their capacity, the technologies might be undervalued leading to missed economic deployment opportunities. The large differences in costs between the FCON and REF scenarios are a direct result of the FCON scenario omitting important spur lines associated with new wind and solar capacity deployment in the FCON scenario and, perhaps, overestimating spur line costs in the REF scenario due to lower spatial resolution in the non-focus region BAs. In either case, new methods are needed using geospatial analysis to inform the correct representation of spur lines in CEMs.

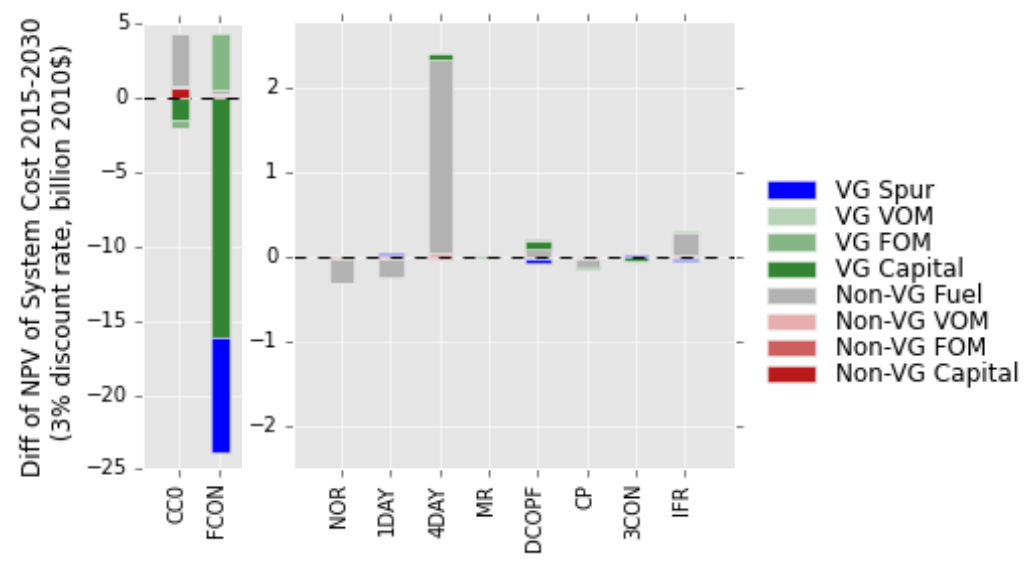

Figure 24. Differences in the NPV of system costs (relative to the REF scenario) in all 10 singlefeature sensitivities 


\subsection{Emissions}

Figure 25 presents differences in $2030 \mathrm{CO}_{2}$ emissions between the sensitivity scenarios and the REF scenario. Not surprisingly, differences in $\mathrm{CO}_{2}$ emissions directly reflect the differences in annual generation presented in Section 5.2. For comparison, in the REF scenario, 2030 systemwide $\mathrm{CO}_{2}$ emissions total 308 million metric tons.

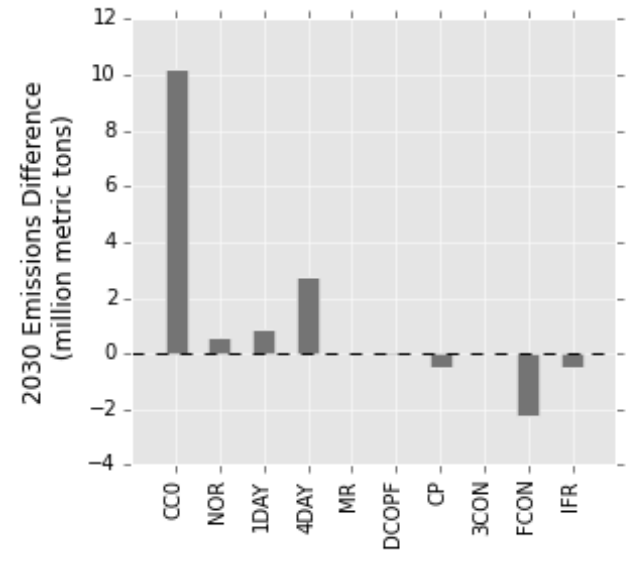

Figure 25. Differences in Western Interconnection annual $\mathrm{CO}_{2}$ emissions in 2030 (relative to the REF scenario) 


\section{Conclusions}

In this report, we analyze the impacts of model configuration and detail on resource selection decisions of capacity expansion models (CEMs). CEMs are computational tools used by utility planners seeking the least cost option for planning a system and by researchers or policymakers attempting to understand the effects of various policy implementations. The complexity of CEMs depends upon the resolution of resource and infrastructure data, the simulation horizon, model formulation, and system representation. Because model simplifications are required for any simulation, the effects of various configurations on results and computational complexity are of particular interest to modelers looking to achieve results relevant to various questions surrounding capacity expansion planning. Our analysis focuses on the importance of model configurations - particularly those related to capacity credit, dispatch modeling, and transmission modeling - to the construction of scenario futures. Our analysis is primarily directed toward advanced tools used for utility planning and those impacts that are most relevant to decisions about future renewable capacity deployment.

To serve this purpose, we develop and employ the National Renewable Energy Laboratory's (NREL's) Resource Planning Model (RPM) to conduct a case study analysis of 11 capacity expansion scenarios for the Western Interconnection through 2030. While the analysis results cover the entire Western Interconnection, the model and research are examine in greater detail a region within the interconnection that consists of two balancing areas-Public Service Company of Colorado and Western Area Power Administration Colorado/Missouri-that serve load primarily in and around the state of Colorado. We examine how model investment decisions change under different model configurations and assumptions related to renewable capacity credit, the inclusion or exclusion of operating reserves, dispatch period sampling, transmission power flow modeling, renewable spur line costs, and the ability to import and export power.

For all scenarios modeled, we find that under market conditions where new renewable deployment is predominantly driven by renewable portfolio standards, model representations of renewable capacity credit and interactions between balancing areas can be most influential in avoiding investments in excess thermal capacity. We also compare computation time between configurations to inform computational tradeoffs and accuracy. From this analysis, we find that certain advanced dispatch representations (e.g., DC optimal power flow) can have dramatic adverse effects on computation time but can be largely inconsequential to investment outcomes, at least at the renewable penetration levels modeled. Finally, we find that certain underappreciated aspects of new capacity investment decisions and model representations thereof, such as spur lines for new renewable capacity, can influence model outcomes particularly in the renewable technology and location chosen by the model. Though this analysis is not comprehensive and results are specific to the model region, input assumptions, and optimization framework employed, the findings are intended to provide a guide for model improvement opportunities. Other findings include:

- A lack of accounting for renewable capacity credit can lead to sub-optimal, highercost portfolios and to an improper economic valuation of new renewable capacity. Simple methods exist to approximate capacity credit, and they can be compared with more sophisticated methods. When no capacity credit is estimated for wind or solar PV, an 
additional 1,800 MW of NG-CT capacity is needed and 6,000 MW of wind is not economically chosen for the Western Interconnection by 2030

- Co-optimization with load balancing and operating reserves enables more accurate estimates of generator availability. Absent a model representation of operating reserve requirements, coal-fired generation increases at the expense of natural gas-fired generation.

- Increasing sampled dispatch periods can have a dramatic effect on computation time while having little apparent effect on resource selection. The inclusion of chronological and longer dispatch periods expose greater variability in the system; however, at the renewable penetration levels modeled, investment decisions are largely unchanged. Changing model configurations to sample 96 hours for each non-peak dispatch period instead of 24 hours increases RPM computation time by nearly two orders of magnitude.

- Transmission-limited accessibility to high quality renewable resources can be revealed by sophisticated transmission modeling in CEMs (e.g., DCOPF); however, the effects are small and the computation expenses are great. On the other hand, ignoring pipe-flow constraints can lead to more significant over-estimates of the accessibility and economic competitiveness of high quality renewable resources, which may understate the renewable capacity needed to meet RPS obligations. Including DCOPF techniques can extend computation time by an order of magnitude and increase wind capacity by less than $50 \mathrm{MW}$ by 2020 in the CO-centric focus region. Ignoring transmission constraints garners little computational benefit and can result in nearly $250 \mathrm{MW}$ of additional wind capacity in the CO-centric focus region by 2030 compared to the REF scenario.

- Transmission spur lines can be an important driver for different renewable options. High spatial resolution can mitigate spurious results driven by improper estimations of spur line distances. Eliminating spur lines costs completely yields an additional $17 \mathrm{GW}$ of wind capacity at the expense of $29 \mathrm{GW}$ of solar capacity in the Western Interconnection by 2030 , but few differences are found in the focus region.

- Disallowing interactions with neighboring regions potentially leads to costly new capacity investment decisions and reduced revenue opportunities for existing generators. When electricity trades in/out of the CO-centric focus region are not permitted, an additional $70 \mathrm{MW}$ of new NG-CT capacity is found while lower-cost generation from $\mathrm{NG}-\mathrm{CC}$ and coal-fired units decrease.

Our analysis identifies potential areas of refinement in existing state-of-the-art electric system scenario development tools. These findings are derived from results of the case study modeling analysis with RPM. They are specific to the system and conditions analyzed, and they can vary accordingly. While we do not analyze input technology, fuel, or policy conditions that would lead to higher renewable penetration levels, we speculate that some of the findings may not extrapolate to those regimes. In particular, more research to develop computational solutions or heuristics to better represent the impacts of high renewables on system operations may be needed as key operational characteristics diverge from today's system. In another example, the cost and value of operating reserves and flexibility may change under higher renewable conditions, CEMs may need to evolve to better capture these changes. Finally, as transmission availability becomes more constrained or as more remote resources are needed, computationally practical solutions may be required to better reflect transmission planning and power flow. 


\section{References}

Arizona Public Service. 2012. 2012 Integrated Resource Plan. http://www.aps.com/library/ resource\%20alt/2012ResourcePlan.pdf.

Aspen/E3 (Aspen Environmental Group, Energy and Environmental Economics, Inc.). 2008. Survey of Utility Resource Planning and Procurement Practices for Application to Long-Term Procurement Planning in California. San Francisco: California Public Utilities Commission.

Avista. 2011. 2011 Electric Integrated Resource Plan. http://www.avistautilities.com/inside/ resources/irp/electric/Documents/2011\%20Electric\%20IRP.pdf.

Castro, Rui MG, and Luís AFM Ferreira. 2001. "A Comparison between Chronological and Probabilistic Methods to Estimate Wind Power Capacity Credit." Power Systems, IEEE Transactions on 16 (4): 904-909.

De Sisternes, Fernando J., and Mort D. Webster. 2013. Optimal Selection of Sample Weeks for Approximating the Net Load in Generation Planning Problems.

DeCesaro, Jennifer, Kevin Porter, and Michael Milligan. 2009. "Wind Energy and Power System Operations: A Review of Wind Integration Studies to Date." The Electricity Journal 22 (10): $34-43$.

U.S. Department of Energy (DOE). (2012). SunShot Vision Study. Washington, DC: U.S. Department of Energy.

Duque, Juan C., Luc Anselin and Sergio J. Rey. 2012. “The max-p-regions problem.” Journal of Regional Science 52 (3): 397-419.

EIPC (Eastern Interconnect Planning Collaboration). Phase 2 Report: DOE Draft - Parts 2-7 Interregional Transmission Development and Analysis for Three Stakeholder Selected Scenarios. http://www.eipconline.com/uploads/20130103 Phase2Report_Part2_Final.pdf.

Energy Information Administration (EIA). (2014). Annual Energy Outlook 2014 with Projections to 2040. Washington, DC: U.S. Energy Information Administration.

Ela, E., V. Gevorgian, P. Fleming, Y.C. Zhang, M. Singh, E. Muljadi, A. Scholbrook, J. Aho, A. Buckspan, L. Pao, V. Singhvi, A. Tuohy, P. Pourbeik, D. Brooks, and N. Bhatt. 2014. Active Power Controls from Wind Power: Bridging the Gaps. Golden, CO: National Renewable Energy Laboratory. NREL/TP-5D00-60574.

Ensslin, Cornel, Michael Milligan, Hannele Holttinen, Mark O’Malley, and Andrew Keane. 2008. "Current Methods to Calculate Capacity Credit of Wind Power, IEA Collaboration." In Power and Energy Society General Meeting-Conversion and Delivery of Electrical Energy in the 21st Century, 2008 IEEE, 1-3. http://ieeexplore.ieee.org/xpls/abs_all.jsp?arnumber=4596006.

Foley, A.M.; B.P. O Gallachoir, J. Hur, R. Baldick, and E.J. McKeogh. (2010). "A Strategic Review of Electricity Systems Models." Energy 35; 4522-4530. 
Getman, Dan, Anthony Lopez, Trieu Mai, and Mark Dyson. Forthcoming. "Methodology for Clustering High-Resolution Spatiotemporal Solar Resource Data." Golden, CO: National Renewable Energy Laboratory.

Hurlbut, D. J.; Haase, S.; Brinkman, G.; Funk, K.; Gelman, R.; Lantz, E.; Larney, C.; Peterson, D.; Worley, C.; Liebsch, E. (2012). Navajo Generating Station and Air Visibility Regulations: Alternatives and Impacts (Revised). NREL/TP-6A20-53024. Golden, CO: National Renewable Energy Laboratory.

Idaho Power. 2011. 2011 Integrated Resource Plan.

LADWP (Los Angeles Department of Water and Power). 2011. 2011 Integrated Resource Plan.

Lew, D.; Brinkman, G.; Ibanez, E.; Florita, A.; Heaney, M.; Hodge, B. M.; Hummon, M.; Stark, G.; King, J.; Lefton, S. A.; Kumar, N.; Agan, D.; Jordan, G.; Venkataraman, S. (2013). Western Wind and Solar Integration Study Phase 2. NREL/TP-5500-55588. Golden, CO: National Renewable Energy Laboratory.

Liu, A., B.H. Hobbs, J. Ho, J.D. McCalley, V. Krishnan, M. Shahidepour, and Q.P. Zheng. 2013. Co-optimization of Transmission and Other Supply Resources. Prepared for Eastern Interconnection States' Planning Council. National Association of Regulatory Utility Commissioners. http://www.naruc.org/grants/Documents/Co-optimization-Whitepaper_Final_rv1.pdf

Lopez, Anthony, Billy Roberts, Donna Heimiller, Nate Blair, and Gian Porro. 2012. U.S. Renewable Energy Technical Potentials: A GIS-Based Analysis. Golden: CO. National Renewable Energy Laboratory. NREL/TP-6A20-51946.

Ma, Juan, Vera Silva, Regine Belhomme, Daniel S. Kirschen, and Luis F. Ochoa. 2013. "Evaluating and Planning Flexibility in Sustainable Power Systems." IEEE Transactions on Sustainable Energy 4(1): 200-208.

MacQueen, J. 1967. "Some Methods for Classification and Analysis of Multivariate Observations." Proceedings of the Fifth Berkeley Symposium on Mathematical Statistics and Probability. 1: 281-297.

Madaeni, Seyed Hossein, Ramteen Sioshansi, and Paul Denholm. 2012. Comparison of Capacity Value Methods for Photovoltaics in the Western United States. Golden, CO: National Renewable Energy Laboratory. NREL/TP-6A20-54704.

Mai, Trieu, Easan Drury, Kelly Eurek, Natalie Bodington, Anthony Lopez, and Andrew Perry. 2013. Resource Planning Model: An Integrated Resource Planning and Dispatch Tool for Regional Electric Systems. Golden, CO: National Renewable Energy Laboratory. NREL/TP6A20-56723.

Milligan, Michael, and Brendan Kirby. 2009. Calculating Wind Integration Costs: Separating Wind Energy Value from Integration Cost Impacts. Golden, CO: National Renewable Energy Laboratory. NREL/TP 550-46275. 
Milligan, Michael, Erik Ela, Hodge Bri-Mathias, Brendan Kirby, Debra Lew, Charlton Clark, Jennifer DeCesaro, and Kevin Lynn. 2011. Cost-Causation and Integration Cost Analysis for Variable Generation. Golden, CO: National Renewable Energy Laboratory. NREL/TP 550051860.

Mills, Andrew D., and Ryan H. Wiser. 2012. An Evaluation of Solar Valuation Methods Used in Utility Planning and Procurement Processes. Berkeley, CA: Ernest Orlando Lawrence Berkeley National Laboratory. LBNL-5933E.

Nahmmacher, Paul, Eva Schmid, Lion Hirth, and Brigitte Knopf. 2014. Carpe Diem: A Novel Approach to Select Representative Days for Long-Term Power System Models with High Shares of Renewable Energy Sources. USAEE Working Paper No. 14-194.

NREL (National Renewable Energy Laboratory). 2007. National Solar Radiation Database 1991-2005 Update: User's Manual. Golden, CO: National Renewable Energy Laboratory. NREL/TP-581-41364.

Nelson, James, Josiah Johnston, Ana Mileva, Matthias Fripp, Ian Hoffman, Autumn PetrosGood, Christian Blanco, and Daniel M. Kammen. 2012. "High-Resolution Modeling of the Western North American Power System Demonstrates Low-Cost and Low-Carbon Futures." Energy Policy 43: 436-447.

NERC (North American Electric Reliability Corporation). 2011. 2011 Summer Reliability Assessment. Atlanta, GA: North American Electric Reliability Corporation.

http://www.nerc.com/files/2011\%20Summer\%20Reliability\%20Assessment_FINAL.pdf.

NERC (North American Electric Reliability Corporation). 2013. 2013 Summer Reliability Assessment. Atlanta, GA: North American Electric Reliability Corporation. http:/www.nerc.com/pa/RAPA/ra/Reliability\%20Assessments\%20DL/2013SRA_Final.pdf.

PacifiCorp. 2011. 2011 Integrated Resource Plan. http://www.pacificorp.com/es/irp.html.

Palmintier, Bryan S. 2013. Incorporating Operational Flexibility into Electric Generation Planning: Impacts and Methods for System Design and Policy Analysis. Boston, MA:

Massachusetts Institute of Technology. http://dspace.mit.edu/handle/1721.1/79147.

Perez, Richard, Mike Taylor, Tom Hoff, and J. P. Ross. 2008. "Reaching Consensus in the Definition of Photovoltaics Capacity Credit in the USA: A Practical Application of Satellitederived Solar Resource Data." Selected Topics in Applied Earth Observations and Remote Sensing, IEEE Journal of 1(1): 28-33.

PNM (Public Service Company of New Mexico). 2011. Electric Integrated Resource Plan 2011-2030. http://www.pnm.com/regulatory/pdf_electricity/irp_2011-2030.pdf.

Portland General Electric. 2009. Integrated Resource Plan 2009.

http://www.portlandgeneral.com/our_company/energy_strategy/resource_planning/docs/irp_nov 2009.pdf. 
Saha, Amlan. 2013. "Review of Coal Retirements." M.J. Bradley \& Associates, LLC. Presentation dated August 12, 2013.

Seattle City Light. 2012. 2012 Integrated Resource Plan. http://www.seattle.gov/light/news/ issues/irp/docs/SCL_2012_IRP.pdf.

Shawhan, D.L. Taber, John T., Di Shi, Ray D. Zimmerman, Jubo Yan, Charles M. Marquet, Yingying Qi, Biao Mao, Richard E. Schuler, William D. Schulze, and Daniel Tylavsky. 2014. "Does a Detailed Model of the Electricity Grid Matter? Estimating the Impacts of the Regional Greenhouse Gas Initiative." Resource and Energy Economics 36 (1): 191-207.

Short, W.; Sullivan P.; Mai T.; Mowers M.; Uriarte C.; Blair N.; Heimiller, D.; Martinez A. 2011. Regional Energy Deployment System (ReEDS). Golden, CO: National Renewable Energy Laboratory. NREL/TP-6A20-46534.

Sigrin, B., Sullivan, P., Ibanez, E., \& Margolis, R. (2014, June). Representation of the solar capacity value in the ReEDS capacity expansion model. InPhotovoltaic Specialist Conference (PVSC), 2014 IEEE 40th (pp. 1480-1485). IEEE.

Sioshansi Ramteen, and Paul Denholm. 2010. "Value of Plug-In Hybrid Electric Vehicles as Grid Resources.” Energy Journal (31:3): 1-23.

NREL SolarPACES (2014). "Concentrating Solar Power Projects." Online Database. Accessed April 22, 2014. http://www.nrel.gov/csp/solarpaces/.

Sterling, John, Joyce McLaren, Mike Taylor, and Karlynn Cory. 2013. Treatment of Solar Generation in Electric Utility Resource Planning. Golden, CO: National Renewable Energy Laboratory. NREL.TP-6A20-60047.

Sullivan, P.; Eurek, K.; Margolis, R. 2014. Advanced Methods for Incorporating Solar Energy Technologies into Electric Sector Capacity-Expansion Models: Literature Review and Analysis. Golden, CO: National Renewable Energy Laboratory. NREL/TP-6A20-61185.

System Advisor Model Version 2015.1.30 (SAM 2015). National Renewable Energy Laboratory. Golden, CO. Accessed March 12, 2015.

Tri-State Generation \& Transmission. 2010. 2010. Integrated Resource Plan/Electric Resource Plan.

Ventyx. (2010). "Energy Market Data." Accessed June 4, 2013:

http://www.ventyx.com/velocity/energy-market-data.asp.

Welsh, Manuel, Paul Deane, Mark Howells, Brian O. Gallachoir, Fionn Rogan, Morgan Bazilian, and Hans-Holger Rogner. 2014. "Incorporating Flexibility Requirements Into Longterm Energy System Models: A Case Study on High Levels of Renewable Electricity Penetration in Ireland." Applied Energy 135: 600-615. 
Western Electricity Coordinating Council (WECC). 2012. Assumptions Matrix for the 2020 Transmission Expansion Planning Policy Committee (TEPPC) Dataset. http://www.wecc.biz/ library/StudyReport/Documents/Assumptions \%20Matrix \%20for\%20the\%202020\%20TEPPC \%20Dataset.pdf.

Western Electricity Coordinating Council (WECC). 2013. 2020 Common Case Transmission Expansion Planning Policy Committee (TEPPC). http://www.wecc.biz/committees/BOD/ TEPPC/20120106/default.aspx?InstanceID=1.

Western Electricity Coordinating Council (WECC). 2014. Load and Resources Subcommittee (LRS). http://www.wecc.biz/committees/StandingCommittees/PCC/LRS/

Shared\%20Documents/Public Data/.

Wilson, Rachel, and Bruce Biewald. 2013. Best Practices in Electric Utility Integrated Resource Planning. Regulatory Assistance Project. http://www.synapse-energy.com/Downloads/ SynapseReport.2013-06.RAP.Best-Practices-in-IRP.13-038.pdf.

Wilkerson, Jordan, Peter Larsen, and Galen Barbose. 2013. Survey of Western U.S. Electric Utility Resource Plans. Berkeley, CA: Ernest Orlando Lawrence Berkeley National Laboratory. LBNL-6545E.

Xcel Energy. 2011. Public Service Company of Colorado: 2011 Electric Resource Plan. http://www.xcelenergy.com/staticfiles/xe/Regulatory/Regulatory\%20PDFs/PSCo-ERP2011/Exhibit-No-KJH-1-Volume-1.pdf. 


\section{Appendix - Comparison of RPM Results with Historical Generation}

In this appendix, we compare the 2010 dispatch results from the modeled REF scenario with historical values provided by the Energy Information Administration (EIA) and from the Environmental Protection Agency's Emissions \& Generation Resource Integrated Database (eGRID). Because EIA data are only found for generation located in the United States, for comparisons with EIA, we include generation from regions primarily located in only the U.S. portion of the Western Interconnection. More specifically, we total the generation results from all BAs represented in RPM excluding BCTC, AESO, and CFE, which include infrastructure primarily located in Canada and Mexico, and we compare them with data provided in EIA Form 923 for 11 Western states: Arizona, California, Colorado, Idaho, Montana, Nevada, New Mexico, Oregon, Utah, Washington, and Wyoming. We compare annual 2010 generation values for six different technology categories: coal, natural gas, nuclear, hydropower, wind, and other renewable technologies. ${ }^{56}$ Additionally, we compare the 2010 eGRID $^{57}$ data for the WECC and Rocky Mountain Reserve Group (RMRG) NERC region/subregion with the RPM system-wide and focus region results, respectively.

For the geographic extent described above, Figure A shows the 2010 generation mix from the dispatch decisions in the RPM REF scenario (purple) and data reported by the EIA (green) and eGRID (red). At a high level, a comparison of the charts in Figure A indicates that RPM's dispatch decisions generally follow the historical generation patterns found in the Western United States: coal was the largest provider of electricity in 2010 , followed by natural gas, hydropower, nuclear, and non-hydropower renewables. In addition to the general alignment in generation ratios, the total amount of generation are also similar between the RPM results (without the three BAs mentioned previously) totaling $723.8 \mathrm{TWh}$ and the EIA reported total of 725.4 TWh, while eGRID reported 723.6 TWh. The EPA-tracked historical generation numbers

\footnotetext{
${ }^{56}$ The mapping of RPM model technologies to these categories is straightforward. For the EIA historical data, we assign each of the prime mover/technology categories to one of the eight general categories. This mapping from Form 923 is as follows: "DFO.DFO.GT" = "Other", "NG.NG.GT" = "CT", "WAT.HYC.HY" = "Hydro", "NG.NG.ST" = "Gas Steam", "SUB.COL.ST" = "Coal", "WAT.HPS.PS" = "PHES", "DFO.DFO.ST" = "Other", "SUN.SUN.PV" = "PV Fixed", "NG.NG.CA" = "CC", "NG.NG.CS" = "CC", "NG.NG.CT" = "CC", "RFO.RFO.GT" = "Other", "SUN.SUN.OT" = "PV Rooftop", "SUN.SUN.ST" = "CSP", "RFO.RFO.ST" = "Other", "BIT.COL.ST" = "Coal", "LFG.MLG.ST" = "Biomass", "WO.WOO.ST" = "Other", "DFO.DFO.CA" = "CC", "DFO.DFO.CT" = "CC", "DFO.DFO.IC" = "Other", "NG.NG.IC" = "CT", "RFO.RFO.IC" = "Other", "OG.OOG.ST" = "Gas Steam", "GEO.GEO.ST" = "Geothermal", "JF.WOO.GT" = "Other", "NUC.NUC.ST" = "Nuclear", "OBG.ORW.ST" = "Biomass", "WDS.WWW.ST" = "Biomass", "SUB.COL.IC" = "Coal", "WND.WND.WT" = "Wind", "LFG.MLG.IC" = "Biomass", "OG.OOG.CA" = "CC", "SC.COL.ST" = "Coal", "GEO.GEO.BT" = "Geothermal", "OBG.ORW.IC" = "Biomass", "MSB.MLG.ST" = "Coal", "MSN.OTH.ST" = "Coal", "LFG.MLG.CA" = "Biomass", "OBG.ORW.CA" = "Biomass", "LFG.MLG.CT" = "Biomass", "OBG.ORW.CT" = "Biomass", "OG.OOG.CT" = "CC", "OBG.ORW.GT" = "Biomass", "PG.OOG.GT" = "Other", "PC.PC.ST" = "Coal", "TDF.OTH.ST" = "Other", "LFG.MLG.GT" = "Biomass", "KER.WOO.GT" = "Other", "WH.OTH.ST" = "Other", "AB.ORW.ST" = "Biomass", "PG.OOG.ST" = "Coal", "WC.WOC.ST" = "Coal", "JF.WOO.CA" = "CC", "JF.WOO.CT" = "CC", "OG.OOG.GT" = "Other", "BLQ.WWW.ST" = "Biomass", "SLW.ORW.ST" = "Biomass", "WO.WOO.CA" = "CC", "WO.WOO.CT" = "CC", "OTH.OTH.ST" = "Other", "NG.NG.OT" = "Other", "OTH.OTH.OT" = "Other", "WH.OTH.OT" = "Other", "BIT.COL.IC" = "Coal", "PC.PC.IC" = "Other", "OTH.OTH.IC" = "Other", "NG.NG.FC" = "Other", "OBG.ORW.FC" = "Biomass".

${ }^{57}$ See www.epa.gov/cleanenergy/energy-resources/egrid/.
} 
align more closely to the RPM 2010 simulations, in part due to the more accurately defined boundaries.

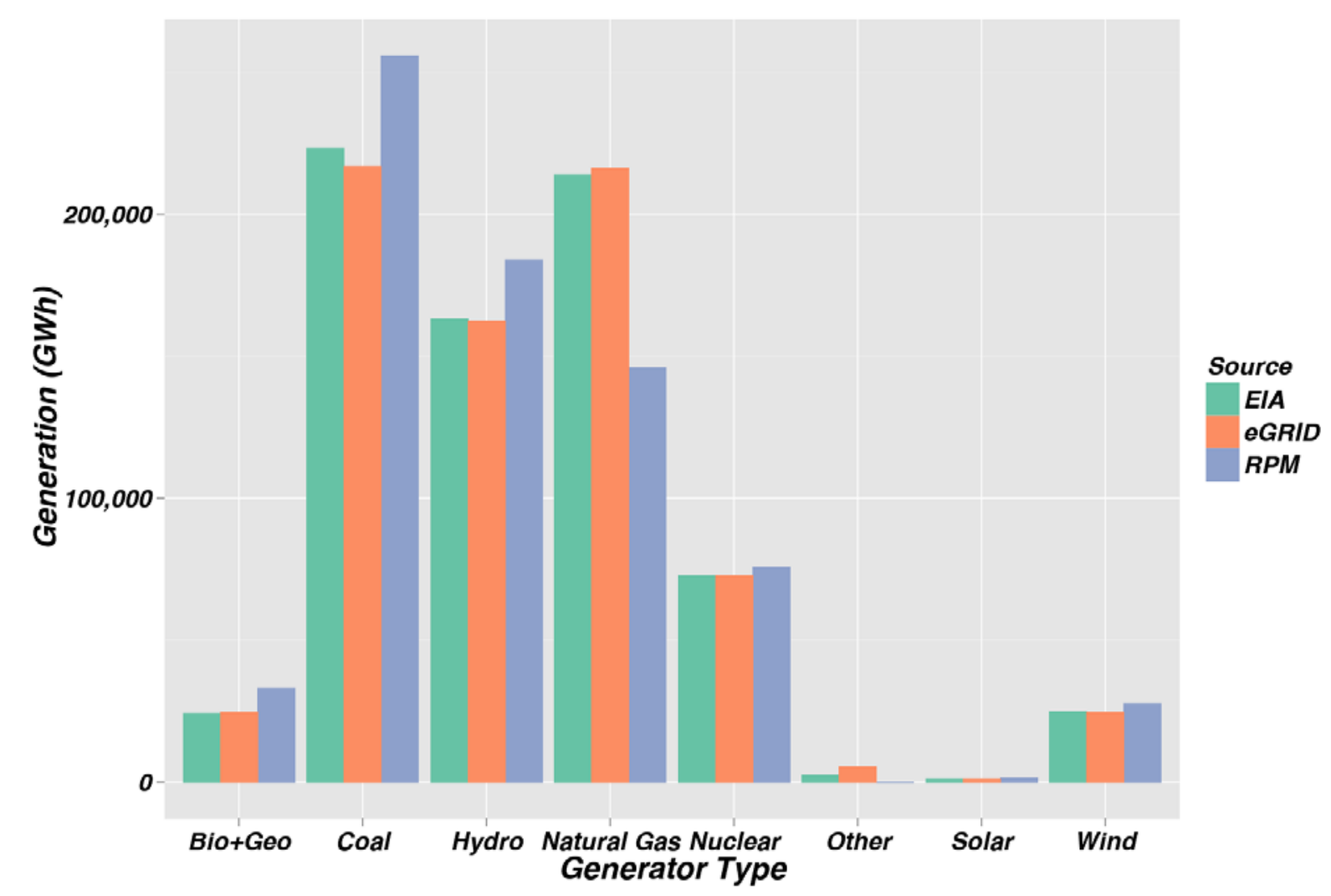

Figure A. Annual generation for 2010: historical EIA and EPA (eGRID) data, and RPM results from the REF scenario

In addition to system wide annual generation shown in Figure A, the eGRID data provides annual generation by generator type for the NERC subregion that aligns with the RPM COcentric focus region (RMRG). Comparing the focus region generation (Figure B) values indicate that RPM aligns better with historical generation for this region. Specifically, the eGRID annual generation figure for the RMRG region is 65.2 TWh, and RPM simulates 66.9 TWh. Based on the similar annual generation numbers between RPM and the EPA eGRID historical data, annual emissions are also similar. RPM estimates 337 million metric tons $\mathrm{CO}_{2}$ in 2010 for the entire Western Interconnection and 53.8 million metric tons $\mathrm{CO}_{2}$ for the $\mathrm{RMRG}$ region, compared with 344 and 61.8 million metric tons $\mathrm{CO}_{2}$, for the respective region/subregions, in the eGRID data. 


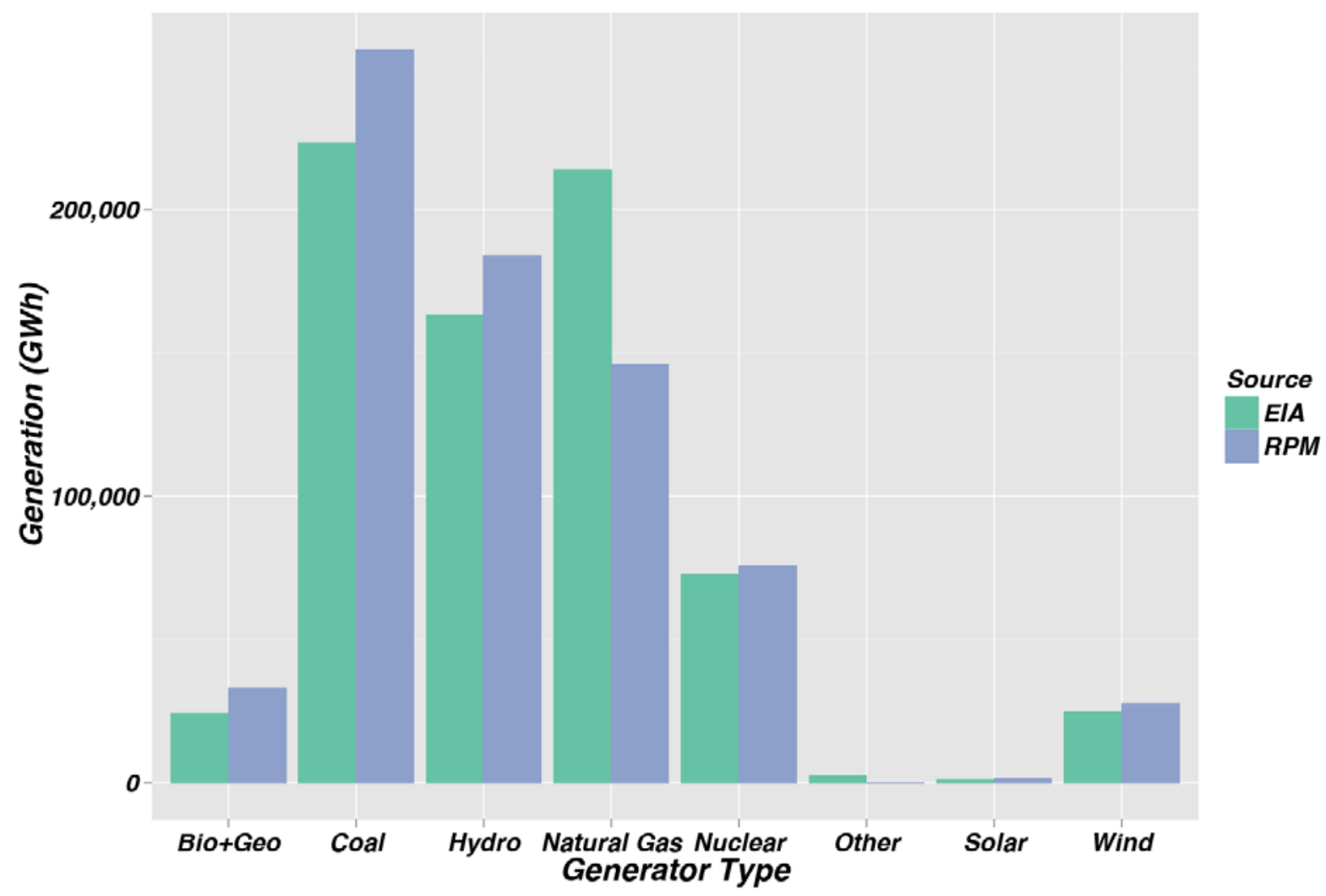

Figure B. Annual generation for 2010: historical EPA (eGRID) data and the RPM REF scenario for the RMRG focus region

While general alignment with historical values is observed in RPM results for 2010, certain key differences are shown by Figures A and B. First, as is typical in many optimized dispatch models, RPM's dispatch algorithm tends to include a bias for coal units over natural gas units, which have higher operating costs. Figures A and B both indicate that coal generation in RPM is roughly 5 percentage points higher than the EIA and EPA data suggest, while natural gas generation is 9 percentage points lower, as a fraction of annual system generation. When looking only at focus region generation numbers, these relative differences grow on a percentage basis to over-predicting coal by 11 percentage points and under-predicting natural gas generation by 13 percentage points. Second, modeled hydropower generation is 3 percentage points higher than the EIA and EPA historical values (1.6 percentage points within the focus region). Some explanations for these differences include:

- The comparison with EIA data is imperfect due to the different spatial extents of the two data sources being compared. More particularly, the EIA data are based on state boundaries, which do not align with Balancing Authority Areas. In addition, the set of units included in RPM (which is directly based on the modeling conducted by Lew et al. 2013) does not perfectly overlap with units considered by EIA. Nonetheless, the close match in total generation implies that there is significant overlap in generation units considered. 
- Historical fuel prices, particularly natural gas prices, vary between units and throughout the year whereas RPM models the same fuel price across all generators that use the same fuel.

- Available hydropower generation in RPM reflects the long-term average electricity provided by hydropower units in the Western Interconnection, which differs from the 2010 historical value. While the water available for hydropower generation can vary significantly from year to year, the long-term average is needed in the model to better reflect the long-term investment decisions.

- Exchanges between balancing areas do not perfectly reflect the 2010 interactions in the Western Interconnection. While we include hurdle rates for electricity transfers between BAs, RPM optimizes across the entire interconnection simultaneously, whereas historical practices depend more strongly on local decisions.

- $\quad$ RPM does not represent self-scheduling decisions, must-run status, or other contractual obligations that might impact plant dispatch. In addition, while the model represents multiple energy and ancillary services in its economic dispatch, the modeled dispatch decisions does not include all real dispatch criteria. For example, plant dispatch driven by frequency response and automated generation control (AGC) signals are not considered in RPM.

- Other model simplifications that would also cause differences in dispatch results include the aggregation of units to technology capacity categories in the zonal representation, the sampling of dispatch periods instead of the full 8,760 hourly (or even subhourly) representation, and the implied flat heat rate curves represented in the model.

These differences notwithstanding, the 2010 results indicate that the RPM dispatch decisions are generally similar to historical practice. In addition, some of the factors that drive model differences with historical results are not as important for future scenarios; for example, the uncertainty in future natural gas prices outweighs differences between generators and across seasons. Finally, the analysis presented in this report focuses on a comparison of scenarios and thus model-driven biases tend to be reduced when differences are evaluated. For these reasons, RPM provides an effective tool for the analysis presented in this report, recognizing the caveats associated with the model and the need for future work to understand their impacts. 